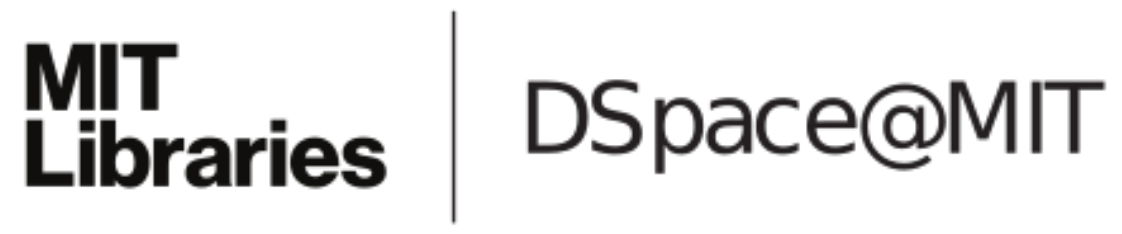

\author{
MIT Open Access Articles
}

Comparison of fouling propensity between reverse osmosis, forward osmosis, and membrane distillation

The MIT Faculty has made this article openly available. Please share how this access benefits you. Your story matters.

Citation: Tow, Emily W. et al. “Comparison of Fouling Propensity Between Reverse Osmosis, Forward Osmosis, and Membrane Distillation." Journal of Membrane Science 556 (June 2018): 352-364 (c) 2018 Elsevier B.V.

As Published: https://doi.org/10.1016/j.memsci.2018.03.065

Publisher: Elsevier

Persistent URL: http://hdl.handle.net/1721.1/115270

Version: Author's final manuscript: final author's manuscript post peer review, without publisher's formatting or copy editing

Terms of use: Creative Commons Attribution-Noncommercial-Share Alike 


\title{
Comparison of fouling propensity between reverse osmosis, forward osmosis, and membrane distillation
}

\author{
Emily W. Tow ${ }^{\mathrm{a}}$, David M. Warsinger ${ }^{\mathrm{a}}$, Ali M. Trueworthy ${ }^{\mathrm{a}}$, Jaichander Swaminathan ${ }^{\mathrm{a}}$, \\ Gregory P. Thiel ${ }^{\mathrm{a}}$, Syed M. Zubair ${ }^{\mathrm{b}}$, Allan S. Myerson ${ }^{\mathrm{c}}$, John H. Lienhard V ${ }^{\mathrm{a}}$ \\ ${ }^{a}$ Rohsenow Kendall Heat Transfer Laboratory \\ Department of Mechanical Engineering \\ Massachusetts Institute of Technology \\ Cambridge, Massachusetts 02139, USA \\ ${ }^{b}$ Mechanical Engineering Department \\ King Fahd University of Petroleum \& Minerals \\ Dhahran 31261, Saudi Arabia \\ ${ }^{c}$ Department of Chemical Engineering \\ Massachusetts Institute of Technology \\ Cambridge, Massachusetts 02139, USA
}

\begin{abstract}
Resistance to fouling is often cited as an advantage of emerging desalination technologies such as forward osmosis and membrane distillation over the widely-used reverse osmosis process. However, the nature and magnitude of differences in fouling behavior between these three processes are not well characterized. This study directly compares the fouling and scaling behavior of reverse osmosis (RO), forward osmosis (FO), and direct contact membrane distillation (MD) in the same membrane module under identical hydrodynamic conditions (flux and cross-flow velocity). Fouling experiments were conducted using calcium sulfate as a model inorganic foulant and alginate as a model organic foulant. Although all three processes tolerated some degree of feed supersaturation for $36 \mathrm{~h}$ without inorganic fouling (scaling), FO exhibited the greatest scaling resistance, withstanding a feed of $33 \pm 2$ $\mathrm{mM} \mathrm{CaSO}{ }_{4}$ without significant flux decline. Scaling occurred at similar concentrations at the membrane between MD and RO; however, while MD tolerated a more concentrated bulk feed due to reduced concentration polarization, flux decline after fouling was considerably more severe in MD. In contrast, MD tolerated organic fouling much better than FO or RO: despite accumulating a similar quantity of alginate gel over $18 \mathrm{~h}$ of operation, flux declined only $14 \%$ in $\mathrm{MD}$ versus $46-47 \%$ in $\mathrm{RO}$ and FO. These results are explained with respect to differences in temperature, membrane materials, and transport mechanisms between the three processes. Although FO and MD each exhibited superior resistance to one type of foulant, neither process outperformed RO in resistance to both organic and inorganic fouling. These findings inform a more nuanced approach to process selection for the treatment of complex water sources.
\end{abstract}

Keywords: desalination, forward osmosis, fouling resistance, membrane distillation, reverse osmosis

E.W. Tow, D.M. Warsinger, J. Swaminathan, A.M. Trueworthy, G.P. Thiel, S.M. Zubair, A.S. Myerson, and J.H. Lienhard, "Comparison of fouling propensity between reverse osmosis, forward osmosis, and membrane distillation,” J. Membrane Sci., 556: 352-364, 15 June 2018. 


\section{Nomenclature}

a Activity [-]

C Concentration $\left[\mathrm{mol} / \mathrm{m}^{3}\right]$

$C_{0} \quad$ Final flux loss [-]

$c_{p} \quad$ Specific heat capacity at constant pressure $[\mathrm{J} / \mathrm{kg}-\mathrm{K}]$

$D_{h} \quad$ Channel hydraulic diameter $[\mathrm{m}]$

$D_{s} \quad$ Salt diffusion coefficient $\left[\mathrm{m}^{2} / \mathrm{s}\right]$

$\Delta G^{*}$ Gibbs energy barrier for nucleation $[\mathrm{J}]$

$\bar{h} \quad$ Average heat transfer coefficient $\left[\mathrm{W} / \mathrm{m}^{2}-\mathrm{K}\right]$

$h_{f g} \quad$ Latent heat of vaporization $[\mathrm{J} / \mathrm{kg}]$

$\bar{J}_{w} \quad$ Average water flux $[\mathrm{m} / \mathrm{s}]$

$k \quad$ Thermal conductivity $[\mathrm{W} / \mathrm{m}-\mathrm{K}]$

$\bar{k} \quad$ Average mass transfer coefficient $[\mathrm{m} / \mathrm{s}]$

$k_{B} \quad$ Boltzmann constant $[\mathrm{J} / \mathrm{K}]$

$K_{s p} \quad$ Solubility product [-]

$l \quad$ Channel length $[\mathrm{m}]$

$N \quad$ Number density of molecules $\left[\mathrm{m}^{-3}\right]$

$P \quad$ Pressure $[\mathrm{Pa}]$

$P_{v} \quad$ Vapor pressure $[\mathrm{Pa}]$

$Q^{\prime} \quad$ Heat transfer per unit width $[\mathrm{W} / \mathrm{m}]$

$R \quad$ Universal gas constant $[\mathrm{J} / \mathrm{mol}-\mathrm{K}]$

$T \quad$ Temperature $[\mathrm{K}]$

$t_{\text {ind }} \quad$ Nucleation induction time $[\mathrm{s}]$

*Address all correspondence to lienhard@mit.edu Journal of Membrane Science 
$\begin{array}{ll}v & \text { Bulk cross-flow velocity }[\mathrm{m} / \mathrm{s}] \\ V_{m} & \text { Molar volume of liquid water }\left[\mathrm{m}^{3} / \mathrm{mol}\right]\end{array}$

Greek

$\delta \quad$ Thickness $[\mathrm{m}]$

$\mu \quad$ Dynamic viscosity [Pa-s]

$\nu \quad$ Kinematic viscosity $\left[\mathrm{m}^{2} / \mathrm{s}\right]$

$\rho \quad$ Density $\left[\mathrm{kg} / \mathrm{m}^{3}\right]$

$\tau \quad$ Time constant $[\mathrm{s}]$

Dimensionless numbers

$\mathrm{Gz}_{H} \quad$ Heat transfer Graetz number [-]

$\mathrm{Gz}_{M}$ Mass transfer Graetz number [-]

$\overline{\mathrm{Nu}}$ Average Nusselt number [-]

Pr Prandtl number [-]

Re Reynolds number [-]

Sc Schmidt number [-]

$\overline{\text { Sh }}$ Average Sherwood number [-]

SI Saturation index [-]

Subscripts

$b \quad$ Bulk liquid

$f \quad$ Feed

in Inlet

m Membrane

out Outlet 
$p \quad$ Permeate

$w \quad$ Water

Acronyms

CTA Cellulose triacetate

DCMD Direct contact membrane distillation

FO Forward osmosis

ICP Internal concentration polarization

MD Membrane distillation

RO Reverse osmosis

TFC Thin-film composite

\section{Introduction}

Membrane fouling is a major challenge in the long-term operation of reverse osmosis (RO) desalination systems. The need for better resistance to fouling is often used to justify the development and use of desalination processes with lower energy efficiency, particularly when desalinating water sources considered to have high fouling potential. Membrane distillation (MD) and forward osmosis (FO) are claimed to be more fouling-resistant (see, e.g., Refs. $[1,2,3])$ than the widely used reverse osmosis (RO) desalination process, but they are usually not as energy-efficient $[4,5,6,7]$. Therefore, these desalination systems should be directly compared to understand how (and how much) their fouling behaviors differ. While fouling has been studied extensively in RO, FO, and MD systems individually, the present study undertakes the first direct comparison of fouling behavior between MD, RO, and FO operated under identical hydrodynamic conditions.

Figure 1 illustrates the working principles of RO, FO, and MD systems. RO desalination uses high hydraulic pressure (typically between 10 and 0 bar), to overcome the osmotic 

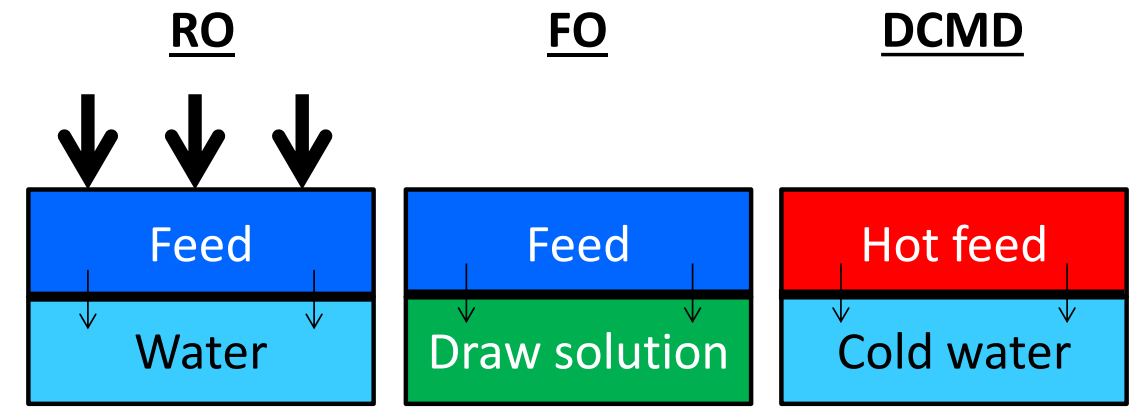

Figure 1: Schematic diagram of the operating conditions of desalination membranes in the systems considered: reverse osmosis (RO), forward osmosis (FO), and direct contact membrane distillation (MD). Thick arrows indicate high hydraulic pressure in RO and fine arrows indicate water flux through the membrane.

pressure of the feed and drive nearly-pure water through a semipermeable membrane whose pores have radii on the order of $0.25 \mathrm{~nm}$ [8]. FO desalination uses membranes with a similar pore-size as RO, but FO uses a draw solution of high osmotic pressure to pull water through the membrane without the application of high hydraulic pressure to the feed. For an FO system to produce pure water, an energy-intensive draw regeneration step is required [5]. Direct contact MD (DCMD) is a simple and relatively efficient configuration of MD in which a microporous, hydrophobic, vapor-filled membrane is in direct contact with both a hot feed and cooler permeate, as described in Refs. $[9,10,11]$. Water evaporates on the feed side of the MD membrane's pores and condenses on the permeate side. Of all the MD configurations, DCMD was chosen to represent MD in this study because, as in RO and FO, the membrane is in contact with liquid on both sides. In each system, the flux of water from the feed bulk toward the membrane drags with it dissolved solutes, suspended solids, and microbes, which can accumulate near the membrane surface, forming a fouling layer and degrading membrane performance.

$\mathrm{MD}$ and FO are generally thought to be more fouling-resistant than RO, but no experiments have been conducted to directly compare MD to either RO or FO. Although MD is frequently portrayed as a fouling-resistant process, reasons for this are poorly understood 
and sometimes not discussed $[12,13]$. A recent review [3] demonstrates that concerns about fouling on MD membranes have historically been dismissed because of low system pressure, relatively large pore size and membrane hydrophobicity. FO has been directly compared to RO in several studies including Refs. $[2,14,15,16,17,18,19,20]$, which have generally found that FO exhibits slower flux decline and is easier to clean. The smoothness and surface chemistry of cellulose triacetate (CTA) membranes as well as the low-pressure operation of FO are typically associated with its fouling resistance. Section 2 explores how membrane properties and operating conditions in $\mathrm{RO}, \mathrm{FO}$, and $\mathrm{MD}$ desalination systems affect fouling behavior.

In this study, we experimentally compare the fouling propensity of $\mathrm{RO}, \mathrm{FO}$, and DCMD using a single cross-flow desalination cell that can be configured for any of the three processes. Flow rates and initial permeate fluxes are kept constant across trials, but each process is operated at its typical operating temperature and pressure. Calcium sulfate is used as a model inorganic foulant and sodium alginate is used as a model organic foulant. Our findings indicate that FO tolerates a significantly higher calcium sulfate concentration without scaling than RO or MD. When scaling does occur, MD exhibits the most rapid flux decline. MD shows significant resistance to organic fouling with alginate relative to $\mathrm{FO}$ and $\mathrm{RO}$, both of which perform similarly. Observed differences in fouling behavior are discussed in relation to the differing membrane properties and operating conditions of RO, FO, and MD desalination systems.

\section{Literature review: Effects of membrane properties and operating conditions on fouling behavior}

RO, FO, and MD all use polymer membranes, but these membranes differ in chemical composition, surface roughness, pore size, support structure, and solvent transport mechanism. Effects of membrane surface properties on fouling are discussed in Sec. 2.1. The 
more subtle effects of the support layer structure and mechanism of solvent transport are discussed in Sec. 2.4.

Differences in standard operating conditions between RO, FO, and MD may also affect fouling behavior. Transmembrane flux is a major driver of fouling due to its advection of foulants toward the membrane and compression of some foulant cakes. For that reason, initial flux is kept constant within each set of trials (inorganic and organic fouling) conducted in this study. However, fouling propensity may also be affected by two other operating conditions that inherently differ between these desalination processes: pressure and temperature. The effects of pressure and temperature on fouling are discussed in Secs. 2.2 and 2.3, respectively.

\subsection{Effect of membrane surface properties}

Membrane scaling risk depends on the residence time of the feed in the desalination system and the nucleation induction times of supersaturated solutes in the feed [21], which are related to membrane wettability [22]. Nucleation induction time, $t_{i n d}$, is related to the concentration, temperature, and Gibbs energy barrier for nucleation $\left(\Delta G^{*}\right)$, which depends on the degree of supersaturation and the surface energy of the solution-membrane, solutioncrystal, and crystal-membrane interfaces [22]. According to classical nucleation theory [23]:

$$
t_{i n d} \propto \frac{1}{N} \exp \left(\frac{\Delta G^{*}}{k_{B} T}\right)
$$

where $N$ is the number density of molecules, $k_{B}$ is the Boltzmann constant, and $T$ is the absolute temperature [24]. Notably, the energy barrier $\Delta G^{*}$ for heterogeneous nucleation on surfaces is substantially larger for low energy surfaces, which tend to be hydrophobic [22]. Therefore, more hydrophobic surfaces such as MD membranes should have longer induction times and be more resistant to gypsum nucleation [22] than surfaces like the polyamide active layer of thin-film composite (TFC) RO membranes, which are hydrophilic [25]. Water-in-air 
contact angle measurements for the active layers of the membranes used in this study are provided in Table 1. For a detailed analysis of the effect of surface wettability on nucleation induction time and scaling propensity, see Ref. [22].

Table 1: Static contact angle of water in air on desalination membrane polymers

\begin{tabular}{cccc}
\hline System & Material & Contact angle & Source \\
\hline MD & Polyvinylidene fluoride (PVDF) & $125^{\circ}$ & {$[22]$} \\
FO & Cellulose triacetate (CTA) & $74.6^{\circ}$ & {$[26]$} \\
RO & Polyamide & $32^{\circ}$ & {$[27]$} \\
\hline
\end{tabular}

In an experimental study of gypsum fouling on FO membranes with different active layer materials, Mi and Elimelech [20] found that CTA membranes with gypsum scaling were more easily cleaned compared to polyamide membranes. They found that the adhesion energy between gypsum and cellulose acetate is lower than gypsum and polyamide (polyamide being commonly used in the active layer of RO membranes), a difference which they attribute to complexation of the $\mathrm{Ca}^{2+}$ in gypsum with the carboxyl groups present on the surface of polyamide membranes. They hypothesize that this difference in adhesion energy leads to crystallization directly on polyamide membranes, whereas crystals form in the bulk when using cellulose acetate membranes under similar conditions.

The fouling behavior of MD membranes is also affected by the presence of large pores containing air and vapor. Previous studies have found that the formation of air layers on MD membranes affects fouling and cleaning due to effects of the liquid-air interface on crystal nucleation and foulant adhesion [22, 28]. Unlike FO and RO membranes, which have subnanometer pores [8] that are smaller than most foulants, MD membranes are susceptible to foulant accumulation inside their pores. The relatively large pores of MD membranes allow pore wetting (entrance of feed solution into the pores), which can lead to solute permeation and a significant decline in permeate quality[29, 30]. However, MD's large pores also permit scaling removal by air backwashing [31]. 


\subsection{Effect of pressure}

$\mathrm{MD}$ and FO are often considered to be less prone to fouling than RO because of their low operating pressure $[2,3,14,15,16]$. However, theoretical modeling has shown that pressure alone does not affect fouling with incompressible foulants [16] such as inorganic scalants (e.g., gypsum) or hydrogel-forming polysaccharides (e.g., alginate [32]). Direct experimental comparisons at fixed flux between RO, FO, and pressurized FO have shown that operating these membrane systems at lower feed hydraulic pressure and higher draw osmotic pressure improves the susceptibility of the membranes to cleaning $[2,14,15,16]$. However, a similar comparison of FO operated at low and high hydraulic pressure with the same flux and draw solution concentration showed no effect of pressure on flux decline rate or cleaning effectiveness $[33,34]$. Previous studies $[2,14]$ have also hypothesized that the low operating pressure of FO allows the foulant layer to be more easily broken up during cleaning. However, our recent studies have shown through in situ visualization that feed hydraulic pressure does not significantly affect mechanisms of alginate fouling removal $[17,33]$.

\subsection{Effect of temperature}

Temperature affects scaling by altering solubility, crystallization kinetics, and concentration polarization. Gypsum increases in solubility with temperature until around $50{ }^{\circ} \mathrm{C}$, after which its solubility begins to decrease [35]. Although calcium sulfate is sometimes considered to have an inverse solubility (solubility that decreases with temperature), its solubility only declines significantly with increasing temperature above approximately 60 ${ }^{\circ} \mathrm{C}$, when crystallization of anhydrite $\left(\mathrm{CaSO}_{4}\right)$ begins to outpace crystallization of gypsum $\left(\mathrm{CaSO}_{4} \cdot 2 \mathrm{H}_{2} \mathrm{O}\right)[35]^{1}$. Although the gypsum saturation concentration does not change substantially over the $20-60{ }^{\circ} \mathrm{C}$ temperature range [35] used in this study, systems will be

\footnotetext{
${ }^{1}$ The exact temperature at which gympsum and anhydrite are equally soluble in water is not established, but lies between approximately $42-60{ }^{\circ} \mathrm{C}$ [35]. However, the "extremely slow crystallization kinetics of anhydrite in aqueous solutions at temperatures below $70^{\circ} \mathrm{C}$ " [35], which have precluded precise determination
} 
compared in terms of both scalant concentration and saturation index (defined in Eq. 3) to account for temperature-related differences in solubility. Increasing temperature also decreases the nucleation induction time at a given saturation index [36, 37, 38], thus accelerating scaling. The maximum calcium sulfate concentration that MD can tolerate without scaling has been shown to decrease with increasing feed temperature [21] due to the reduction in induction time with increasing temperature. On the other hand, diffusion coefficients increase with increasing temperature, reducing concentration polarization and thus reducing the scalant concentration at the membrane for a given feed concentration, flux, and crossflow velocity. MD, therefore, has the advantage of reduced concentration polarization due to its elevated temperature.

Temperature also affects organic fouling. Kim et al. [39] experimentally tested the effect of feed and draw temperature on alginate fouling in FO, and they found that high feed temperature improves antifouling performance by raising the diffusion coefficient of alginate, thereby facilitating alginate transport away from the membrane. High temperatures may also affect organic fouling through denaturation of proteins or depolymerization of polysaccharides, but alginate does not appear to depolymerize at temperatures up to $80{ }^{\circ} \mathrm{C}[40] .{ }^{2}$ Furthermore, due to the proportionality between trans-cake hydraulic pressure drop and water viscosity [41], the decrease in water viscosity that accompanies increasing temperature should reduce the hydraulic pressure drop (which is caused by drag) through a given foulant cake. Overall, higher temperature should reduce the severity of organic fouling with alginate, the model organic foulant used in this study.

of the transition temperature, reduce the likelihood of anhydrite scaling in low-temperature desalination processes such as those used in this study.

${ }^{2} \mathrm{At}$ the temperatures used in this study (up to $70{ }^{\circ} \mathrm{C}$ at the membrane module inlet), alginate gelation should therefore be possible. We determined that alginate gel does not melt in the MD temperature range used in this study by immersing a piece of alginate gel in water above $70{ }^{\circ} \mathrm{C}$ for 10 minutes and boiling the gel for 5 minutes, after which the gel remained intact. 


\subsection{Effect of water transport mechanism}

It is important to consider the mechanisms of water transport in $\mathrm{RO}, \mathrm{FO}$, and $\mathrm{MD}^{3}$ because mechanisms of trans-membrane water transport affect foulant deposition patterns as well as the effect of foulant accumulation on water production. In $\mathrm{FO}$ and $\mathrm{RO}$, water transport is driven by the hydraulic-osmotic pressure difference, $\Delta P-\Delta \pi$, where $\Delta P$ is the difference in pressure between the feed and draw or permeate sides of the active layer, and $\Delta \pi$ is the difference in osmotic pressure between the feed and draw or permeate sides [44]. RO has high hydraulic pressure on the feed side and has atmospheric pressure and negligible osmotic pressure on the permeate side. However, in FO, pressure is typically atmospheric in both feed and draw solutions, and the draw osmotic pressure is high. The porous support layer of the FO membrane has significant mass transfer resistance [45], which causes internal concentration polarization (ICP) and limits the osmotic pressure difference across the active layer of the membrane. Flux in MD is driven by a vapor pressure difference across the hydrophobic membrane's pores, wherein the vapor pressure on the feed side is higher due to the elevated temperature of the feed. The vapor pressure is also influenced by the feed solute concentration and, to a lesser extent, the hydraulic pressure [46]. Refer to She et al. [42] for details of water transport in FO and RO and Summers et al. [43] for a more detaled explanation of water transport in DCMD.

She et al. [42] review flux decline mechanisms due to membrane fouling in osmotic membrane desalination processes, including RO and FO. Although MD does not involve osmosis, some of their findings apply to MD fouling because MD membranes are also salt-rejecting. The formation of a porous cake on the surface of any desalination membranes causes flux decline through cake-enhanced concentration polarization, which raises the osmotic pressure at the membrane. It also causes hydraulic drag, which lowers the hydraulic pressure at the

\footnotetext{
${ }^{3}$ Refer to She et al. [42] for details of water transport in FO and RO and Summers et al. [43] for a more detaled explanation of water transport in DCMD.
} 
membrane. At the low feed concentrations used in this study, the dominant driver of flux decline due to alginate fouling is hydraulic drag [18]. In the case of MD fouling, both cakeenhanced concentration polarization and, to a lesser extent, hydraulic drag have the effect of reducing the vapor pressure at the membrane $[46,47,48]$. Because a temperature difference exists between the feed and permeate, MD is also susceptible to cake-enhanced temperature polarization [3], i.e., fouling layer thermal resistance.

The effect on flux of a particular foulant cake depends on the mass transfer resistance through all layers of the membrane. Flux tends to decline more slowly in FO than in RO, even at the same initial flux, due to the effect of ICP on the overall mass transfer resistance of an FO membrane $[18,19,42]$. Heat and mass transfer through a fouled MD membrane has not, to our knowledge, yet been modeled, but we expect that the effect of foulant accumulation on flux decline in MD will differ from $\mathrm{RO}$ and $\mathrm{FO}$ because of the different transport mechanisms and resistance of the membrane.

The effect of hydraulic pressure drop through the foulant layer on the magnitude of the water transport driving force is different in $\mathrm{MD}$ than in $\mathrm{RO}$ or $\mathrm{FO}$ because of the differing effects of hydraulic pressure on water permeation. Water permeation is driven by a vapor pressure difference in MD and a hydraulic-minus-osmotic pressure difference in RO and FO. The hydraulic-minus-osmotic pressure differences across the active layers in RO and FO are on the order of tens of bars, so each bar of hydraulic pressure drop through the fouling layer has a significant effect on flux in RO and FO. In MD, the effect of hydraulic pressure on vapor pressure (and thus water flux) is weak, but not nonexistent [46, 47, 48]. The hydraulic pressure drop through a layer of hydrophilic foulant such as alginate gel reduces the pressure on the liquid side of the liquid-vapor interface, which occurs where the gel faces a membrane pore opening. This interfacial pressure difference leads to a concave interface with a lower vapor pressure. The difference in vapor $\operatorname{pressure}^{4}, \Delta P_{v}$, caused by an interfacial pressure

\footnotetext{
${ }^{4}$ Relative to the vapor pressure of an identical solution at the same temperature with a flat interface.
} 
difference (equal, in this case, to the hydraulic pressure drop through the foulant layer), $\Delta P$, is [49]:

$$
\Delta P_{v} \simeq \Delta P\left(\frac{P_{v} V_{m}}{R T}\right)
$$

where $V_{m}$ is the molar volume of liquid water, $R$ is the universal gas constant, and $T$ is the absolute temperature at the meniscus. Evaluating Eq. 2 at $60{ }^{\circ} \mathrm{C}$, the ratio $\Delta P_{v} / \Delta P=$ $1.3 \times 10^{-4}$, so the change in vapor pressure at the membrane due to fouling is much smaller than the hydraulic pressure drop through the foulant. In MD, the vapor pressure difference that drives permeation is on the order of 0.1 bar, so a pressure drop of 1 bar through the foulant layer would lead to a change in vapor pressure driving force of approximately $0.1 \%$, according to Eq. 2. As a result of the weak dependence of vapor pressure on liquid pressure, foulant hydraulic resistance is not as important in MD as it is in RO or FO.

\section{Methods}

Fouling behavior was compared between RO, FO, and DCMD processes using the same membrane module at the the same initial flux and cross-flow velocity. Each process was operated within a typical range of temperatures $\left(20-25^{\circ} \mathrm{C}\right.$ for $\mathrm{RO}$ and $\mathrm{FO}$; for $\mathrm{MD}, 60$ ${ }^{\circ} \mathrm{C}$ in the feed and $20{ }^{\circ} \mathrm{C}$ in the permeate loop ${ }^{5}$ ) and pressures (0 bar for $\mathrm{FO}$ and $\mathrm{MD}$; 13.75-27.5 bar for RO) for that technology. To compare the systems in terms of tolerance of supersatuated solutions without scaling, the calcium sulfate feed concentrations at which scaling began to occur in each system were identified by conducting separate $36 \mathrm{~h}$ trials with different feed concentrations. Concentration and saturation index at the membrane were estimated from bulk properties using the heat and mass transfer models summarized in Sec. 3.3. The organic fouling propensity of the three processes was compared by recording the rate of flux decline during $18 \mathrm{~h}$ of operation with the same concentrations of sodium alginate

\footnotetext{
${ }^{5}$ One MD trial $\left(27 \mathrm{mM} \mathrm{CaSO}_{4}\right)$ had a particularly low initial flux, so the permeate-side temperature was reduced from $20{ }^{\circ} \mathrm{C}$ to $18{ }^{\circ} \mathrm{C}$ to augment flux slightly without significantly changing feed conditions.
} 


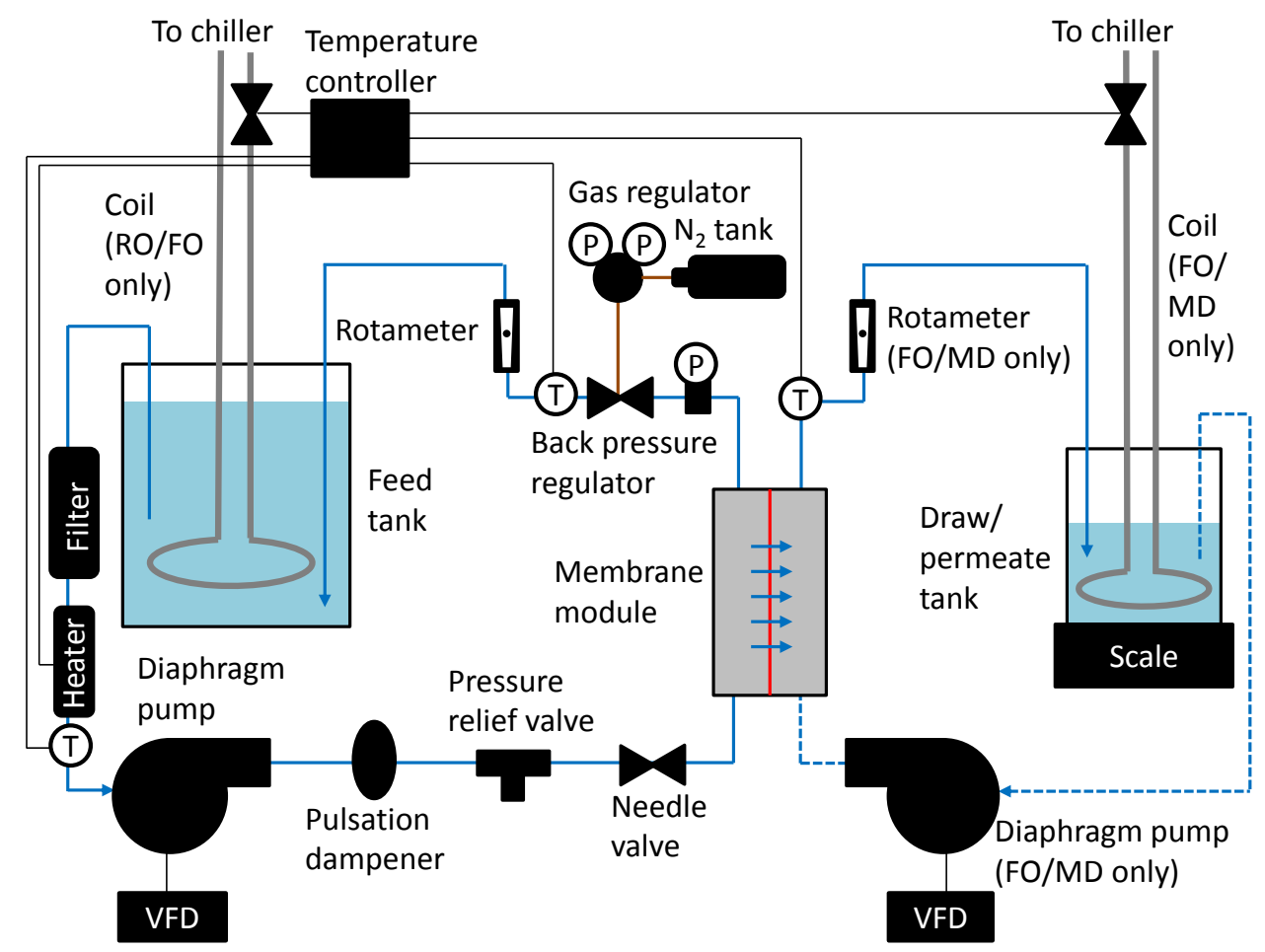

Figure 2: Schematic diagram of experimental apparatus that can be operated as RO, FO, or DCMD. Liquids, wires, and nitrogen gas, are denoted by blue, black, and brown lines, respectively. Dashed blue lines represent flows present only in FO or DCMD. Figure adapted from Ref. [18] to reflect modifications to the apparatus as used in this study.

and calcium chloride. The conditions of all experimental trials are listed in Appendix A.

\subsection{Apparatus}

Membranes were held in a plate-and-frame module within an experimental apparatus (Fig. 2) that could be operated as RO, FO, or DCMD. Both the feed and draw/permeate channels of the membrane module were $1 \mathrm{~mm}$ deep, $80 \mathrm{~mm}$ long, and $30 \mathrm{~mm}$ wide. Transmembrane flux was driven by high feed pressure in RO, high draw solution osmotic pressure in FO, and high feed temperature (and thus vapor pressure) in DCMD. Temperature, crossflow velocity, and feed pressure were controlled while permeate (or draw) mass was recorded to calculate flux and determine the degree of fouling.

The RO and FO configurations of the apparatus used in this study have been described 
in detail elsewhere [18]. The DCMD configuration was similar to FO, except that the draw was replaced with a cold permeate flow loop, and the feed was heated to drive flux through the MD membrane. In DCMD, the permeate flow loop was initially filled with deionized water that had been partially degassed to prevent disruption of the flux measurement by outgassing. Feed temperature was controlled using an in-line cartridge heater based on feedback from a thermocouple downstream of the membrane module. Permeate temperature was controlled using a cooling coil and a thermocouple submerged in the permeate tank. After each MD experiment, the cartridge heater was removed and any accumulated scale was scraped off.

In all configurations, a $2 \mu \mathrm{m}$ (nominal) cartridge filter was used to prevent large crystals from entering the membrane module and causing premature scaling, as demonstrated in Ref. [50]. Flux was calculated from the change in draw/permeate mass over time, which was measured with an Ohaus Scout Pro digital scale, using the RealTerm software package for data aquisition. The mass displaced by the submerged cooling coil and draw/permeate inlet and outlet were accounted for in the FO and MD flux measurement. Draw/permeate mass was recorded every second, but flux was calculated from the change in mass over longer periods. $\mathrm{RO}$ and FO fluxes were reported every 15 minutes from the change in draw/permeate mass during that time period. In MD, fluctuations in permeate production necessitated a longer water production time, so MD flux was reported every 15 minutes based on the change in permeate mass during the previous 30 minutes. Flux measurement uncertainties for this experimental apparatus have been analyzed and reported previously [18].

Commercially-available membranes were used in all three systems. A new membrane sample was used for each trial. RO trials used polyamide thin film composite membranes (Dow FILMTEC SW30HR) designed for seawater applications. In FO, a cellulose triacetate FO membrane (Hydration Technology Innovations CTA-ES) was used. RO and FO 
membranes were prepared by soaking in $50 \%$ ethanol, $50 \%$ water mixture for 5 minutes and in deionized water for at least 30 minutes. The MD membranes were hydrophobic PVDF (Millipore ISEQ00010) with a nominal pore size of $0.2 \mu \mathrm{m}$ and a water contact angle of $125^{\circ}$ [21]. No spacers were used in the feed channel.

\subsection{Fouling procedure}

First, the system (RO, FO, or DCMD) was allowed to run free of foulants until reaching a steady permeate flux. Feed velocities were initially maintained above $10 \mathrm{~cm} / \mathrm{s}$. For the organic fouling tests, $50 \mathrm{mM}$ sodium chloride was added to the feed tank to provide a baseline feed salinity. In DCMD, the feed stream was raised to the desired temperature $\left(60{ }^{\circ} \mathrm{C}\right.$ at the feed channel outlet) while the cold stream was maintained at $20{ }^{\circ} \mathrm{C}$. In $\mathrm{RO}$, the pressure was adjusted to achieve the desired initial flux. In FO, a draw solution of sodium chloride in deionized water is used to drive flow, and the sodium chloride concentration is adjusted until the desired initial flux is achieved. Each system was run for at least $2 \mathrm{~h}$ and until a steady flux was reached before adding foulants.

To instigate inorganic fouling, the feed was brought to supersaturation with calcium sulfate. As in Ref. [21], supersaturated calcium sulfate feed solution was prepared by adding concentrated calcium chloride solution and concentrated sodium sulfate solution (made by dissolving ACS-grade powders from Sigma-Aldrich and EMSURE, respectively, in deionized water) at least ten minutes apart. As a result of the salts used, the $\mathrm{Na}^{+}$and $\mathrm{Cl}^{-}$ concentrations in each feed solution were equal to twice the calcium sulfate concentration. After chemical addition, the feed cross-flow velocity was reduced to $5 \mathrm{~cm} / \mathrm{s}$ to encourage fouling. In FO and DCMD, the draw/permeate stream was also maintained at $5 \mathrm{~cm} / \mathrm{s}$ and the draw/permeate channel was filled with a stack of two non-woven spacers (Sterlitech 17 mil diamond). Once foulants were added, the apparatus was held at constant temperature, pressure, and flow rate for $36 \mathrm{~h}$ or until rapid flux decline clearly indicated that fouling had 
occurred. Feed concentration was maintained within approximately $\pm 5 \% 6$ of the desired concentration by periodically diluting it to its initial volume. For the purpose of comparing $\mathrm{RO}, \mathrm{FO}$, and MD, scaling was determined to have occurred if flux declined to $80 \%$ of initial flux (90\% in FO, which generally exhibits slower flux decline while fouling $[18,19])$ within the $36 \mathrm{~h}$ trial period.

To instigate organic fouling, concentrated sodium alginate solution (mixed from powdered sodium alginate, Sigma A2033) was added to bring the feed up to a final concentration of $200 \mathrm{mg} / \mathrm{L}$ after the system reached a steady flux. Calcium chloride was then added to bring the feed concentration to $1 \mathrm{mM}$ and encourage gelation of the alginate as it concentrated at the membrane (see, e.g., [51]). Fouling was carried out for $18 \mathrm{~h}$ at constant temperature, pressure, and flow rate to enable comparison of flux decline rate. After $18 \pm 0.5$ $\mathrm{h}$, the membrane was removed and a small (approximately $6 \mathrm{~cm}^{2}$ ) panel was cut from the active area and lightly blotted with a tissue, using only surface tension to hold the tissue to the fouled membrane panel. Once blotted, the gel was then peeled off the membrane with the aid of a razor blade and weighed to determine the gel mass per unit area. After weighing, the gel was air-dried and weighed again to determine the dry mass.

\subsection{Predicting conditions at the membrane}

Crystals have the potential to form when the solution is supersaturated with respect to any salt anywhere in the feed, but crystallization is likely to occur first near the membrane where, due to concentration polarization, the solution is most concentrated. Therefore, estimating conditions close to the membrane is necessary to interpret results of the inorganic fouling trials. With the $\mathrm{CaCl}_{2}-\mathrm{Na}_{2} \mathrm{SO}_{4}$ mixtures used in this study, calcium sulfate is the most likely scalant [52]. Gypsum (calcium sulfate dihydrate) is the most likely form of

\footnotetext{
${ }^{6}$ In a few highly supersaturated trials, some crystallization occurred in the feed tank, reducing the feed concentration over time by an unknown amount. However, membrane scaling should precede bulk crystallization due to the higher solute concentration near the membrane, so the feed concentration at the onset of scaling should not have been affected by crystallization in the feed tank.
} 
calcium sulfate to crystallize in the range of temperatures used in this study $\left(20-60{ }^{\circ} \mathrm{C}\right)$, although anhydrite precipitation could potentially occur at the higher temperatures used in the MD trials [35]. The concentration of calcium sulfate with respect to gypsum saturation is quantified with the saturation index, SI, which is defined in Eq. 3 (see, e.g., [52]):

$$
\mathrm{SI}=\log _{10}\left(\frac{a_{\mathrm{Ca}^{2+}} a_{\mathrm{SO}_{4}{ }^{2-}} a_{w}^{2}}{K_{s p}}\right)
$$

where $a_{\mathrm{Ca}^{2+}}, a_{\mathrm{SO}_{4}{ }^{2-}}$, and $a_{w}$ denote the activities of calcium, sulfate, and water, respectively, and $K_{s p}$ is the solubility product for calcium sulfate dihydrate. When $\mathrm{SI}=0$, the solution is saturated with respect to gypsum, and when SI $>0$, the solution is supersaturated.

The gypsum saturation index is calculated from ion concentrations (including sodium and chloride) and solution temperature using the program PHREEQC (USGS [53]) with the PHREEQC database ${ }^{7}$. For calculation of the saturation index near the membrane, where the concentration is highest and crystallization is most likely, the concentration and temperature near the membrane are determined as described in the following two sections.

\subsubsection{Concentration polarization}

The calcium sulfate concentration at the membrane can be estimated from film theory. The recovery ratio (defined as the ratio of permeate flow rate to feed flow rate) of the module is very low $(<1 \%)$, so the bulk concentration can be considered constant throughout the length of the module. Assuming that calcium and sulfate diffuse together (i.e., neglecting the effects of sodium and chloride transport on calcium and sulfate transport) and that all ions are perfectly rejected by the membrane, the average calcium sulfate concentration at the membrane, $\bar{C}_{m}$, can be expressed as a function of the concentration of the feed at the module inlet, $C_{f}$, average (measured) permeate flux, $\bar{J}_{w}$, and average mass transfer

\footnotetext{
${ }^{7}$ SI was also calculated in PHREEQC using the Pitzer database, but the SIs calculated using the two databases differed by less than $10 \%$, so only values from the PHREEQC database were reported.
} 
coefficient in the feed, $\bar{k}_{f}$, using stagnant film theory ${ }^{8}$ (see, e.g., [45]):

$$
\bar{C}_{m}=C_{f} \exp \left(\bar{J}_{w} / \bar{k}_{f}\right)
$$

Although the mass transfer coefficient varies along the length of the membrane as the mass diffusion boundary layer develops, we use an average mass transfer coefficient to characterize the concentration at the membrane in each coupon-scale test. The average mass transfer coefficient is calculated from the mass transfer analog of a Nusselt number correlation [55] for hydrodynamically fully-developed flow between parallel plates with a uniform wall heat flux:

$$
\overline{\mathrm{Sh}}_{D_{h}}= \begin{cases}8.235+0.0364 \mathrm{Gz}_{M} & \mathrm{Gz}_{M} \leq 100 \\ 2.236 \mathrm{Gz}_{M}^{1 / 3}+0.9 & 100<\mathrm{Gz}_{M} \leq 1000 \\ 2.236 \mathrm{Gz}_{M}^{1 / 3} & \mathrm{Gz}_{M}>1000\end{cases}
$$

where $\mathrm{Gz}_{M}$ is the mass transfer Graetz number,

$$
\mathrm{Gz}_{M}=\left(\frac{D_{h}}{l}\right) \operatorname{Re}_{D_{h}} \mathrm{Sc}
$$

and where $\overline{\mathrm{Sh}}_{D_{h}}=\bar{k}_{f} D_{h} / D_{s}$ is the average Sherwood number, $D_{h}$ is the hydraulic diameter (approximated as twice the channel thickness due to this channel's large width:thickness ratio), $l$ is the channel length, $\operatorname{Re}=v D_{h} / \nu$ is the Reynolds number, $v$ is the bulk velocity, $\nu$ is the kinematic viscosity of the solution, and $\mathrm{Sc}=\nu / D_{s}$ is the Schmidt number, $D_{s}$ is the calcium sulfate diffusion coefficient in water. The diffusion coefficient of calcium sulfate at infinite dilution (used here because of the low feed concentrations used in these experiments)

\footnotetext{
${ }^{8}$ Eq. 4 is often derived from a boundary layer transport model without convective terms, i.e., a stagnant film. However, by transforming the boundary layer equations, Zydney [54] showed Eq. 4 is also applicable under less restrictive approximations that do account for convection. Rohlfs et al. [55] extended the analysis to show that the Zydney-transformed equations are analogous to thermal boundary layer equations with a uniform wall heat flux boundary condition. Consequently, our choice for Sh, Eq. 5, is by analogy to a Nusselt number for a thermally developing flow with a uniform wall heat flux.
} 
is calculated from ion diffusion coefficient data from Li and Gregory [56] as $9.11 \times 10^{-10} \mathrm{~m}^{2} / \mathrm{s}$ at $25^{\circ} \mathrm{C}$. Calcium sulfate diffusion coefficients at $20^{\circ} \mathrm{C}$ and $58.5^{\circ} \mathrm{C}$ (the temperatures at the membrane on the feed side in the gypsum scaling tests; see Sec. 3.3.2) are calculated using the Stokes-Einstein equation as $7.98 \times 10^{-10} \mathrm{~m}^{2} / \mathrm{s}$ and $1.89 \times 10^{-9} \mathrm{~m}^{2} / \mathrm{s}$, respectively.

\subsubsection{Membrane temperature}

In $\mathrm{RO}$ and $\mathrm{FO}$, the temperature at the membrane is approximately equal to the feed temperature. However, in DCMD, a temperature difference exists between the bulk liquid and the liquid at the membrane. Additionally, both sensible heat transfer and evaporation of water from the feed cause a streamwise temperature drop in the feed. Calculations in PHREEQC [53] show that gypsum saturation concentration is not strongly dependent on temperature in the $60{ }^{\circ} \mathrm{C} \pm 10^{\circ} \mathrm{C}$ range, so approximate values of average temperature are sufficient to predict saturation indices in MD trials.

Near-membrane temperature is modeled with a simplified version of the DCMD model developed by Summers et al. [43], using the measured average permeate flux rather than a fitted membrane permeability. In the present simplified model, both permeate flux and heat transfer coefficients are treated as uniform along the length of the module, and the calculated temperatures represent approximate average temperatures of the bulk feed and the feed at the membrane.

Sensible heat is considered to be transferred from the feed to the membrane surface by convection, through the membrane by conduction, and then to the permeate stream by convection. Heat fluxes inside and outside the membrane are unequal due to the evaporation of water at the feed side of the membrane and condensation at the permeate side, as described by Eq. 7:

$$
\bar{h}_{f}\left(\bar{T}_{f, b}-\bar{T}_{f, m}\right)=\bar{h}_{p}\left(\bar{T}_{p, m}-\bar{T}_{p, b}\right)=\rho_{p} \bar{J}_{w} h_{f g}+\frac{k_{e f f, m}}{\delta_{m}}\left(\bar{T}_{f, m}-\bar{T}_{p, m}\right)
$$


where $\bar{h}$ is the average heat transfer coefficient, $\bar{T}$ is the average temperature, $\rho$ is the liquid density, $h_{f g}$ is the latent heat of vaporization of water, $k_{e f f, m}$ is the effective membrane thermal conductivity, $\delta$ is the thickness, and subscripts $f, p, b$, and $m$ denote feed, permeate, bulk, and membrane, respectively. The equations above can be solved for the average temperature at the membrane on the feed side by eliminating $\bar{T}_{p, m}$ :

$$
\bar{T}_{f, m}=\frac{\bar{h}_{f}\left(1+\frac{k_{e f f, m}}{\delta_{m} \bar{h}_{p}}\right) \bar{T}_{f, b}+\frac{k_{e f f, m}}{\delta_{m}} \bar{T}_{p, b}-\rho_{p} \bar{J}_{w} h_{f g}}{\bar{h}_{f}\left(1+\frac{k_{e f f, m}}{\delta_{m} \bar{h}_{p}}\right)+\frac{k_{e f f, m}}{\delta_{m}}} .
$$

The effective membrane thermal conductivity $k_{e f f, m}$ is estimated to be $0.06 \mathrm{~W} / \mathrm{m}-\mathrm{K}$ using a porosity of 0.8 [43] and assuming 1-D conduction through a PVDF slab with straight-through pores containing air. Average heat transfer coefficients in the feed and permeate channels $\left(\bar{h}_{f}\right.$ and $\bar{h}_{p}$ ) are calculated using a Nusselt number correlation for hydrodynamically-developed, laminar flow between flat plates at constant temperature [57]:

$$
\overline{\mathrm{Nu}}_{D_{h}}=\frac{\bar{h} D_{h}}{k_{w}}=7.54+\frac{0.03 \mathrm{Gz}_{H}}{1+0.016 \mathrm{Gz}_{H}^{2 / 3}},
$$

where $\mathrm{Gz}_{H}$ is the heat transfer Graetz number,

$$
\mathrm{Gz}_{H}=\left(\frac{D_{h}}{l}\right) \operatorname{Re}_{D_{h}} \operatorname{Pr}
$$

and where $\overline{\mathrm{Nu}}_{D_{h}}$ is the Nusselt number, $k_{w}$ is the thermal conductivity of water, $\operatorname{Pr}=c_{p} \mu / k_{w}$ is the Prandtl number of water, $c_{p}$ is the specific heat capacity of water, and $\mu$ is the dynamic viscosity of water. Because the saturation index is not strongly temperature dependent in the $60{ }^{\circ} \mathrm{C}$ range and thus a precise calculation of membrane temperature is not required, the effect of the non-woven spacers in the permeate channel on the permeate-side heat transfer coefficient is neglected in this analysis.

The axial temperature changes in the hot and cold channels $(\Delta T)$ are also calculated 
to relate the average bulk temperatures in Eq. 8 to the known feed outlet and permeate inlet temperatures. The flow rates of feed and permeate were set equal in this experiment; for the purpose of this estimation, we neglect small changes in channel cross-flow rate due to permeation, differences in density or heat capacity between channels due to temperature and concentration differences, and heat exchange with the environment through the module walls. Therefore, the axial decrease in feed temperature, $\Delta T$, is approximately equal to the increase in permeate temperature. Approximating the heat transfer rate per unit width into the permeate channel as $\dot{Q}^{\prime}=\bar{h}_{f}\left(\bar{T}_{f, b}-\bar{T}_{f, m}\right) l$, the permeate temperature increase is:

$$
\Delta T=\frac{\dot{Q}^{\prime}}{\delta_{c} v \rho_{p} c_{p}}=\frac{\bar{h}_{f}\left(\bar{T}_{f, b}-\bar{T}_{f, m}\right) l}{\delta_{c} v \rho_{p} c_{p}}
$$

where $\delta_{c} W \operatorname{ork}(23)=D_{h} / 2$ is the channel thickness. The average bulk feed and permeate temperatures can then be estimated from the measured values at the feed outlet $\left(T_{f \text {,out }}\right)$ and permeate inlet $\left(T_{p, \text { in }}\right)$ :

$$
\begin{gathered}
\bar{T}_{f, b}=T_{f, \text { out }}+\Delta T / 2 \\
\bar{T}_{p, b}=T_{p, \text { in }}+\Delta T / 2
\end{gathered}
$$

Equations 8-13 are solved simultaneously in MATLAB to estimate average feed temperatures in the bulk and near the membrane. For the experiments conducted in this study, the estimated average feed temperatures in the bulk and near the membrane were 63.9-64.6 ${ }^{\circ} \mathrm{C}$ and $58.4-58.6{ }^{\circ} \mathrm{C}$, respectively. In this temperature range, the saturation concentration (calculated using PHREEQC [53]) varies less than $0.4 \%$ per ${ }^{\circ} \mathrm{C}$, which indicates that differences in SI throughout the channel are primarily driven by concentration polarization, not temperature variation. 


\section{Results}

\subsection{Inorganic fouling}

RO, FO, and DCMD were operated at typical temperatures $\left(20,20\right.$, and $60{ }^{\circ} \mathrm{C}$, respectively) with feeds of various concentrations to determine the maximum calcium sulfate concentration and gypsum saturation index that each system could tolerate without fouling. $\mathrm{RO}$ pressure and $\mathrm{FO}$ draw concentration were adjusted before fouling to match the initial fluxes measured in the MD trials. Operating parameters for all trials are included in Appendix A.

Flux decline measurements for the RO trials at various feed calcium sulfate concentrations are shown in Fig. 3. Flux measurements are normalized by initial flux. Here, the 29 $\mathrm{mM}$ RO trial exhibited rapid flux decline and the $24 \mathrm{mM}$ trial showed a transition to rapid flux decline after approximately $13 \mathrm{~h}$. The delay in the onset of fouling at $24 \mathrm{mM}$ may relate to the induction time for calcium sulfate nucleation (see, e.g., [36]), which increases as SI approaches zero. In trials with concentrations of $22 \mathrm{mM}$ and lower, flux declined gradually during the $36 \mathrm{~h}$ of operation, which was most likely due to membrane compaction over time, as recorded in Ref. [58], rather than external fouling. To ensure that there was no fouling in these lower-concentration trials, the membrane from the highest-concentration trial that did not exhibit rapid flux decline $(22 \mathrm{mM})$ was removed after the experiment and allowed to dry. Visual inspection revealed needle-like crystals only around the edges of the membrane, where it was clamped into the module. The active area of membrane appeared to be free of crystals except for small patches of crystal growth near stagnation points at the channel outlet, and therefore this was considered a non-fouling result. In contrast, RO membranes examined after exhibiting rapid flux decline in contact with more concentrated feed solutions had a fairly uniform layer of small crystals on the active area of the membrane, confirming that the rapid flux decline indicated fouling. The divergence in flux decline rates shown in Fig. 3, along with examination of membranes after use, show that the transition to signifi- 


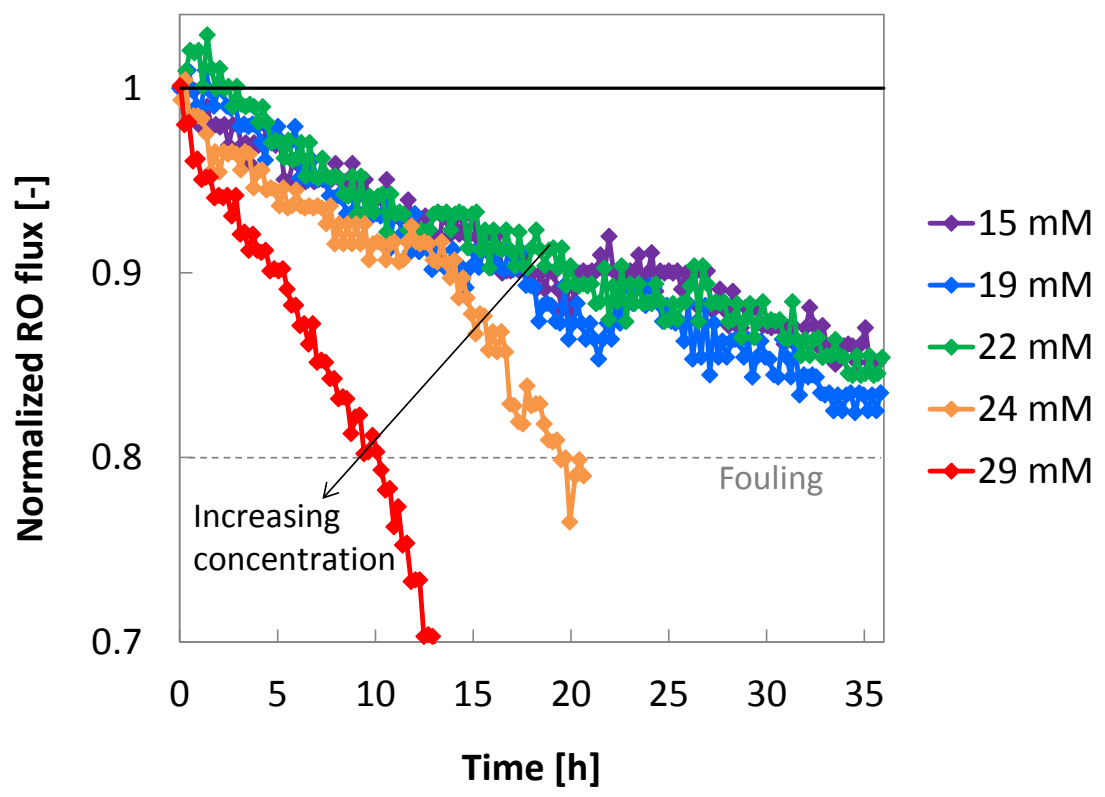

Figure 3: Flux decline in RO with various feed concentrations of calcium sulfate (given in the legend). Initial flux was $19.5 \pm 0.2 \mathrm{LMH}\left(\mathrm{L} / \mathrm{m}^{2}-\mathrm{h}\right)$. The slow flux decline of the $15-19 \mathrm{mM}$ trials is indicative of membrane compaction, not external fouling.

cant RO membrane fouling occurred between feed calcium sulfate concentrations of 22 and $24 \mathrm{mM}$.

Figure 4 shows the normalized flux for all FO trials with calcium sulfate. Here, flux is normalized by the predicted flux in the absence of fouling using the method outlined in [33] to account for dilution of the draw solution over time. Flux declined significantly in trials with at least $36 \mathrm{mM} \mathrm{CaSO}_{4}$ in the feed, whereas no fouling occurred in trials with up to $29 \mathrm{mM}$ $\mathrm{CaSO}_{4}$ in the feed. Fouling results determined from flux decline were corroborated by visual inspection of the membranes, which were covered with a loosely-attached layer of crystals in the $36 \mathrm{mM}$ and $43 \mathrm{mM}$ trials. In the $43 \mathrm{mM}$ trial, which was significantly supersaturated in the bulk feed, crystallization occurred not only on the membrane, but in the feed tank, tubing, and instrumentation, clogging a rotameter and causing an increase in feed hydraulic pressure and the rise in flux around $10 \mathrm{~h}$; when the feed was returned to atmospheric pressure around 16 h, flux dropped rapidly. From these trials, we determined that the transition to 


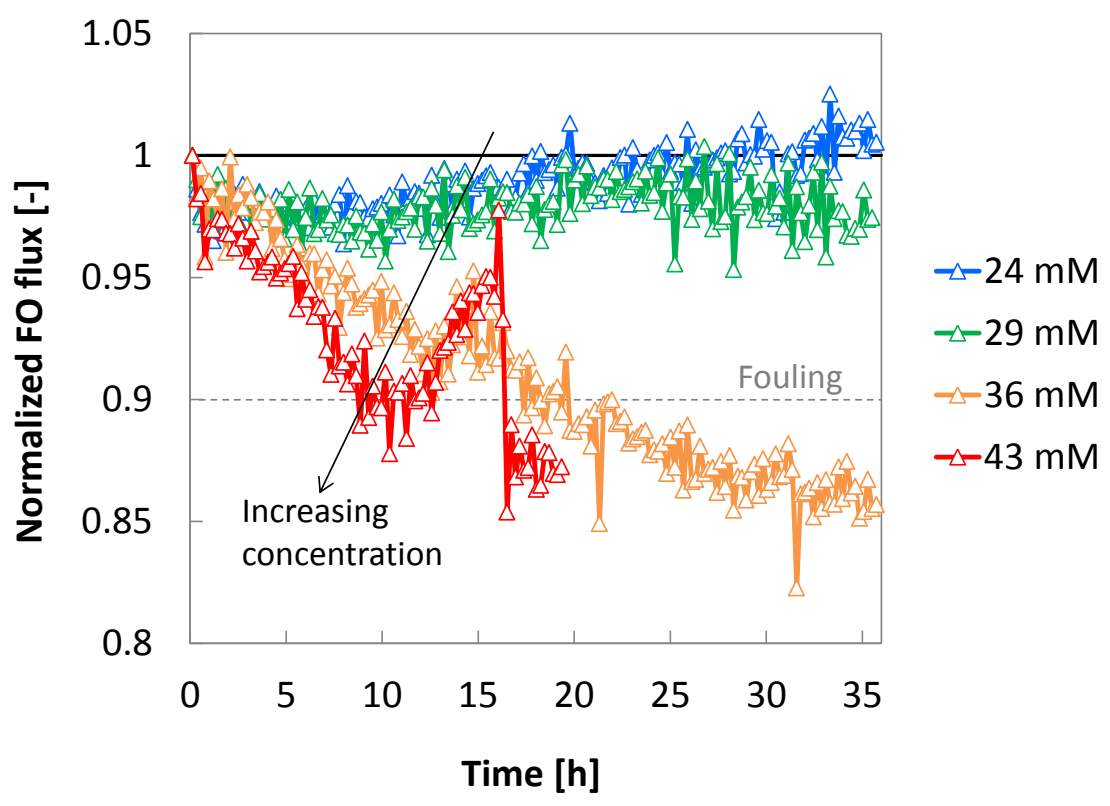

Figure 4: Flux decline in FO with various feed concentrations of calcium sulfate (given in the legend). Initial flux was $19.6 \pm 0.6 \mathrm{LMH}$ in all trials. Clogging of a rotameter by crystals caused a pressure spike and temporary increase in flux from $10-16 \mathrm{~h}$ in the $43 \mathrm{mM}$ trial.

fouling in this FO system occurred between feed calcium sulfate concentrations of 29 and $36 \mathrm{mM}$.

Figure 5 shows the measured flux decline for all MD trials conducted with calcium sulfate. Flux is normalized by initial flux. Trials with feeds of 29 and $36 \mathrm{mM}$ calcium sulfate exhibited a dramatic decline in flux within the first few hours, whereas trials with 24 and $27 \mathrm{mM}$ declined less than $10 \%$ during the $36 \mathrm{~h}$ test period. As with RO, the membrane was removed and dried after the most supersaturated trial that did not exhibit significant flux decline (27 mM); again, crystals were largely confined to the clamped region outside the active area and, to a lesser extent, the channel outlet stagnation point, and this was considered a non-fouling result. A few individual needles were scattered throughout the active area; these may have formed during the trial without significantly affecting flux, or they may have formed while the membrane dried in air after removal from the membrane module. In contrast, the fastest-fouling membrane was carpeted with crystals when it was 


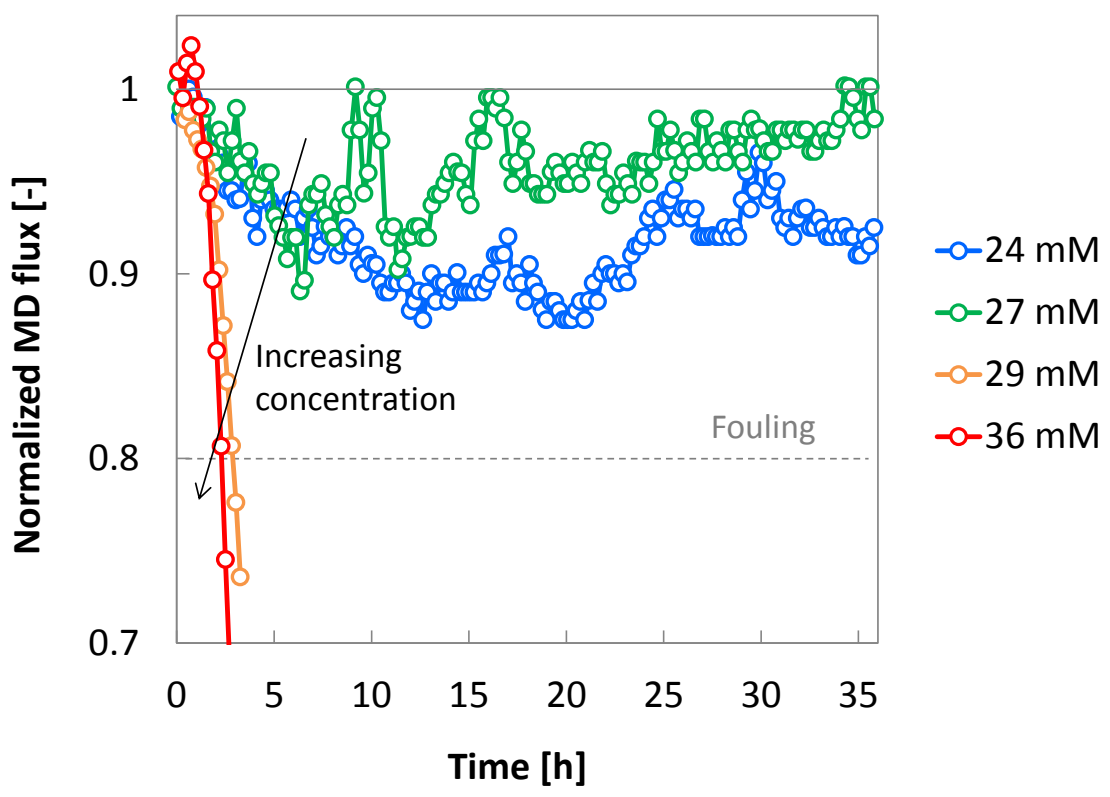

Figure 5: Flux decline in MD with various feed concentrations of calcium sulfate (given in the legend). Initial flux was $18.6 \pm 2.3 \mathrm{LMH}$ in all trials.

removed after just $3 \mathrm{~h}$. The stark difference in fouling behavior (in terms of both crystal accumulation and flux decline rate) places the transition to fouling for this MD system between feed calcium sulfate concentrations of 27 and $29 \mathrm{mM}$.

Figure 6 shows the relative resistance to calcium sulfate fouling of RO, FO, and MD. The maximum concentration tolerated by each system without fouling was determined from the experiments shown in Figs. 3 through 5. The error bars show the range between the highest concentration that did not foul and the lowest concentration that did foul. The concentration and saturation index at the membrane, which are larger due to concentration polarization, were estimated as described in Sec. 3.3.1. The bulk feed concentrations tolerated by each process are not broadly-applicable because the degree of concentration polarization is specific to the present apparatus and chosen operating conditions. Because channel thickness and length have been shown to affect scaling propensity [21] in MD, the values of concentration and saturation index that can be sustained near the membrane without fouling are specific to 


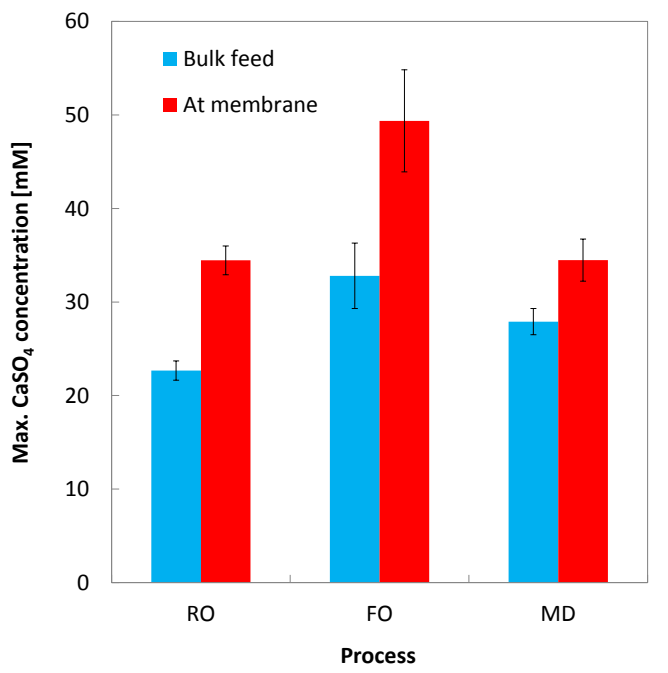

(a) Concentration

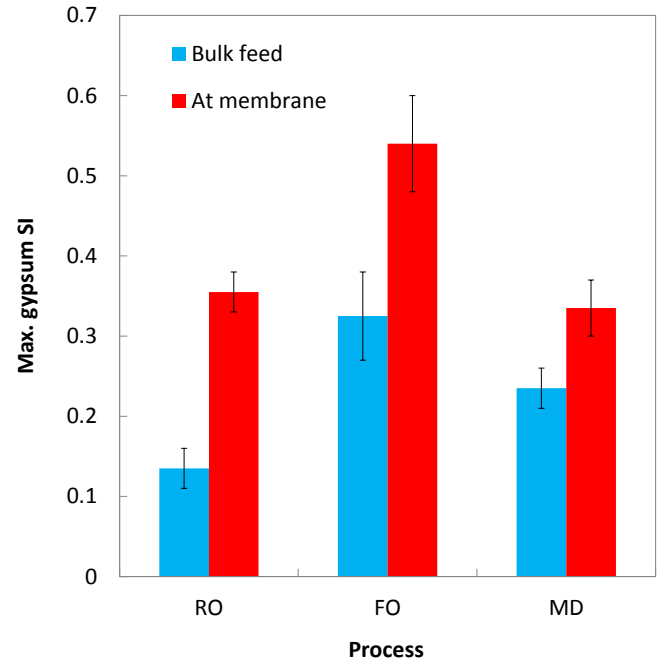

(b) SI

Figure 6: Maximum (a) calcium sulfate concentration and (b) gypsum SI without fouling in RO, FO, and MD. SI is defined in Eq. 3 and SI $>0$ indicates a supersaturated solution. FO tolerates a more concentrated (and more supersaturated) feed without fouling than MD or RO. Error bars represent the range between the lowest concentration that caused fouling and the highest concentration that did not.

this experimental apparatus with its particular channel dimensions. However, these results allow us to discuss the relative performance of these three processes when desalinating supersaturated feeds.

Figure 6 shows that FO tolerated a significantly higher calcium sulfate concentration and gypsum SI both in the feed and at the membrane than either RO or MD. MD tolerated a slightly higher feed concentration than $\mathrm{RO}$, perhaps due to the lessened concentration polarization at higher temperature, but the maximum concentration at the membrane was roughly the same between these two systems. Because the saturation concentration of gypsum is not strongly dependent on temperature in the $20-60{ }^{\circ} \mathrm{C}$ range [35], saturation indices (shown in Fig. 6b) show the same trend as concentrations (Fig. 6a). Notably, all three systems were able to tolerate a somewhat supersaturated feed (SI $>0)$ for $36 \mathrm{~h}$ without scaling.

Differences in supersaturation tolerance between systems shown in Fig. 6 may be ex- 
plained by the differences in membrane chemistry between FO, RO, and MD systems as well as the effect of temperature on nucleation induction time, as discussed in Sec. 2. Based on surface chemistry alone, FO and MD would be expected to have better inorganic fouling resistance than RO (see Sec. 2.1 and Refs. [20, 22]). However, the high temperature of the MD feed reduces the nucleation induction time for a given supersaturation, significantly reducing the SI at which fouling occurs (see Sec. 2.3 and Ref. [21]). MD's high temperature does reduce concentration polarization, allowing MD to tolerate a slightly more supersaturated feed than $\mathrm{RO}$, even though the tolerance of each to supersaturation at the membrane is approximately equal. Overall, favorable surface chemistry and low-temperature operation give FO a significant advantage in gypsum scaling resistance relative to both RO and MD.

The effect of fouling on flux is an important aspect of the fouling propensity of a membrane process. Figure 7 highlights differences in fouling behavior between the three systems by comparing the flux decline data shown in Figs. 3 through 5 at three calcium sulfate concentrations. At $24 \mathrm{mM}$, only the RO membrane fouled. At $29 \mathrm{mM}$, both $\mathrm{RO}$ and $\mathrm{MD}$ membranes fouled; although MD tolerated a higher feed concentration than RO without fouling, the rate of flux decline at $29 \mathrm{mM}$ was much greater in $\mathrm{MD}$ than in RO. At $36 \mathrm{mM}$, both FO and MD membranes fouled ${ }^{9}$, but the rate of flux decline was significantly higher in MD than in FO. The high rate of the MD system's flux decline after the onset of inorganic fouling should be taken in to consideration when choosing a desalination process to treat supersaturated water sources.

Disparities in flux decline rate after fouling between MD and the osmotic membrane systems can be attributed to differences in operating temperature and fouling mechanisms, as previously discussed in Sec. 2. In contrast to multi-stage flash (MSF) distillation and multieffect distillation (MED), which minimize scaling by separating the evaporating interface from solid surfaces by means of a spray and a falling film, respectively, MD places the

\footnotetext{
${ }^{9} \mathrm{RO}$ was not tested at $36 \mathrm{mM}$ because it began fouling at a much lower concentration of $24 \mathrm{mM}$.
} 


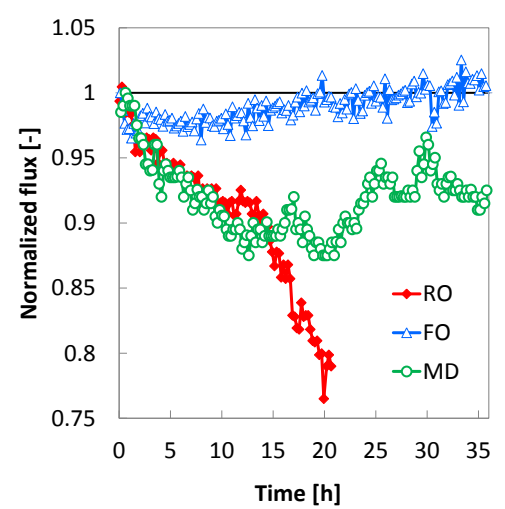

(a) $24 \mathrm{mM}$

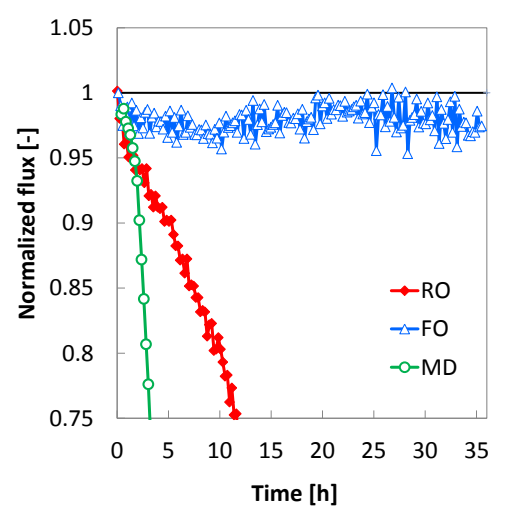

(b) $29 \mathrm{mM}$

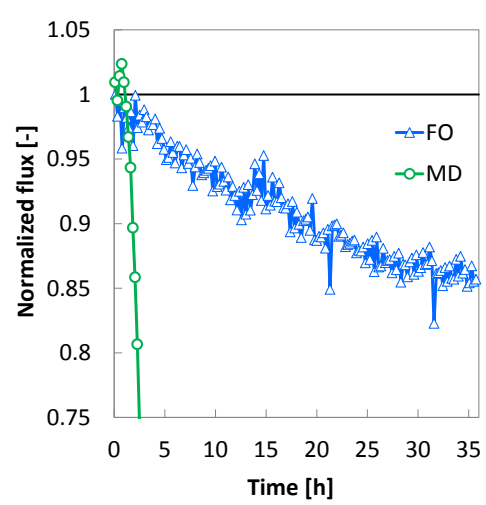

(c) $36 \mathrm{mM}$

Figure 7: Comparison of flux decline behavior between different processes at three calcium sulfate feed concentrations. Initial flux was 19.5 $\pm 0.7 \mathrm{LMH}$.

evaporating interface in direct contact with the most sensitive part of the membrane, the pore. Scale formation at the pore entrance is therefore likely. The effect of scale formation at the MD pore entrance may also differ from the effect of scale on top of an $\mathrm{RO}$ or FO membrane due to the different water transport mechanisms of these processes (see Sec. 2.4): in MD, a small volume of scale inside the pore may significantly inhibit vapor flow. The faster crystallization kinetics at high temperature (see, e.g., [36]) may also contribute to the rapid flux decline of scaled MD membranes (see Sec. 2.3).

The low rate of fouling-induced flux decline in FO-particularly in comparison to RO, which is also a dense membrane at low temperature - appears to be primarily related to the FO membrane's scaling-resistant surface chemistry. The rate of flux decline in FO at $36 \mathrm{mM} \mathrm{CaSO}_{4}$ (Fig. 7c) is lower than in $\mathrm{RO}$ at $29 \mathrm{mM}$ (Fig. 7b), even though the foulant concentration in the $\mathrm{FO}$ trial is higher. $\mathrm{FO}$ and $\mathrm{RO}$ do differ in their response to the accumulation of equivalent foulant layers [18] due to different levels of membrane mass transfer resistance (see Sec. 2.4), but the stark difference in flux decline rate is well beyond what can be explained by the ICP self-compensation effect. However, slow flux decline might be explained by the CTA FO membrane material's resistance to crystal nucleation, which 


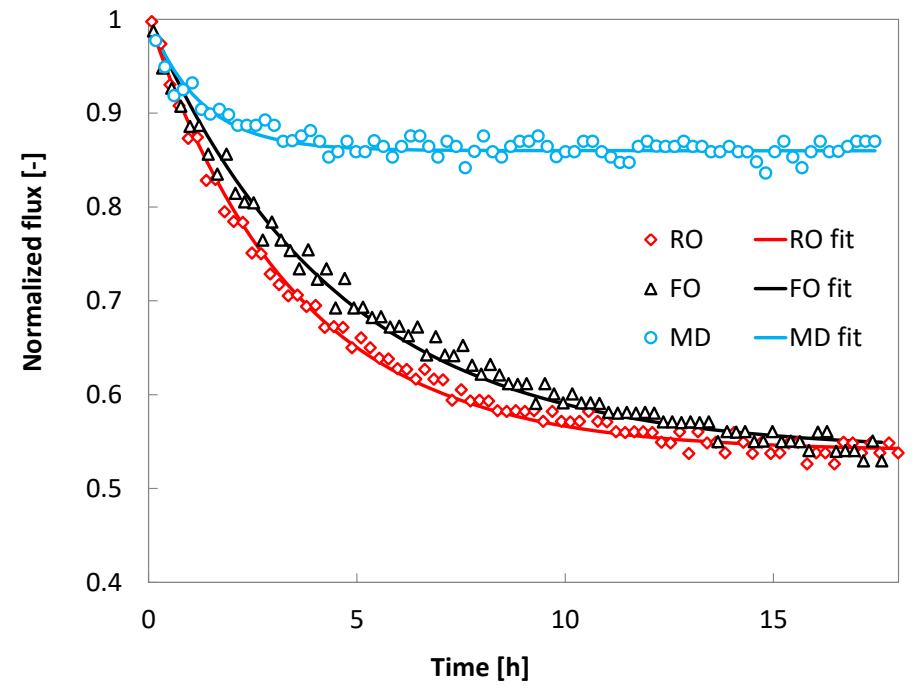

(a) Flux

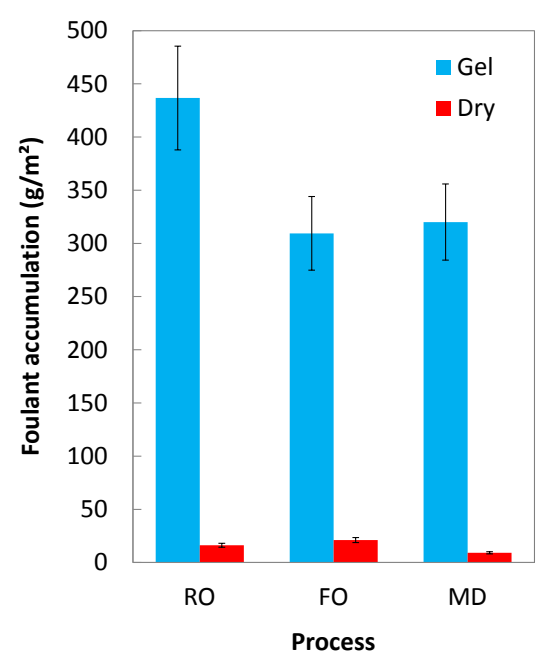

(b) Accumulation

Figure 8: Comparison of (a) flux decline and (b) foulant accumulation in RO, FO, and MD due to alginate fouling in the presence of calcium $\left(1 \mathrm{mM} \mathrm{CaCl}_{2}\right)$ with $50 \mathrm{mM} \mathrm{NaCl}$. Initial flux was $17.7 \pm 1.0 \mathrm{LMH}$. Exponential fits (Eq. 14) are included in (a). In (b), "gel" refers to the mass of gel accumulated on the membrane and "dry" refers to the mass of that gel after air drying. Error bars are based on $10 \%$ uncertainty in mass and $5 \%$ uncertainty in area.

was demonstrated by Mi and Elimelech [20] and discussed in Sec. 2.1. The crystallizationresistant FO membrane surface may reduce the area fraction of crystal-membrane contact when scaling does occur, keeping more of the membrane surface active and perhaps even enhancing removal of loosely-attached crystals through shear-induced diffusion or inertial lift (see, e.g., [59]).

\subsection{Organic fouling}

Measurements of the flux decline resulting from alginate fouling in RO, FO, and MD are presented in Fig. 8a. Exponential fits of flux decline follow Eq. 14 and the constants $C_{0}$ and $\tau$ in Table 2:

$$
J^{*}=1-C_{0}\left[1-\exp \left(\frac{-t}{\tau}\right)\right]
$$

$J^{*}$ is the ratio of flux to initial flux. The exponential shape of the flux decline fit is derived from a deposition-minus-removal model of heat exchanger fouling that has been applied to 
Table 2: Fitted constants for Eq. 14

\begin{tabular}{ccc}
\hline Process & Final flux loss, $C_{0}$ & Time constant, $\tau[\mathrm{s}]$ \\
\hline RO & 0.46 & 12600 \\
FO & 0.48 & 1800 \\
MD & 0.14 & 4500 \\
\hline
\end{tabular}

fouling in reverse osmosis [60]; validation of this model for fouling in FO and MD are not known to the authors, but the agreement with the shape of the experimental flux decline curves is relatively good.

Figure $8 \mathrm{a}$ and Table 2 show that the three systems foul with different time constants and approach different normalized fluxes. Although the initial rate of flux decline is fairly similar between all three systems, MD quickly reaches an asymptotic flux of $14.5 \mathrm{LMH}$, whereas RO and FO have longer time constants and end at similar fluxes of 9.2 LMH and 9.9 LMH, respectively. The slower flux decline of RO relative to FO is expected based on FO's ICP self-compensation effect (see Sec. 2.4 and Refs. [18, 19, 42]). The comparable asymptotic flux of RO and FO is expected given the identical feed composition, temperature, and hydrodynamic conditions, according to the critical flux model [61], and the insensitivity of alginate fouling to operating pressure (see Sec. 2.2 and Ref. [33]).

The significant increase in asymptotic flux in MD relative to $\mathrm{RO}$ and FO trials with the same feed composition (and thus the same foulant advection rate at a given flux) implies a larger foulant removal rate in MD. Given the small size of organic macromolecules such as alginate (on the scale of nm [59]), Brownian diffusion is likely to be the dominant removal mechanism [59]. Using the Stokes-Einstein equation and the temperature dependence of the viscosity of pure water, the diffusion coefficient of alginate can be estimated to increase by a factor of 2.1 between $25{ }^{\circ} \mathrm{C}$ and $58.5{ }^{\circ} \mathrm{C}$, which are the temperatures in the feed close to the membrane in $\mathrm{FO} / \mathrm{RO}$ and $\mathrm{MD}$, respectively. According to Ref. [59], this difference in diffusion coefficient should lead to an increase in Brownian diffusion rate by a factor of 1.75 between $25^{\circ} \mathrm{C}$ and $58.5^{\circ} \mathrm{C}$, assuming constant alginate concentration in the gelled 
foulant layer. This estimate corresponds to an increase in asymptotic flux from 9.2 LMH (measured in RO) to 16.0 LMH, which is close to the 14.5 LMH asymptotic flux measured in MD. Therefore, the higher asymptotic flux in MD can be attributed, at least in part, to the higher diffusion coefficient of alginate at elevated temperature.

Figure $8 \mathrm{~b}$ shows the mass of alginate gel deposited on the membranes as well as the dry mass of that gel measured after several weeks of air drying. The dry mass of the gel collected in the FO trial was greater than that of the RO trial, as would be expected given its slower flux decline and higher average flux, which brings more alginate to the membrane [18]. In contrast, the measured mass of gel on the FO membrane was the smallest of the three membranes. ${ }^{10}$ The quantity of foulant accumulation (both as gel and dry mass) was almost as high in $\mathrm{MD}$ as in RO, despite the high asymptotic flux of MD. Accumulated alginate gel does not affect water flux as much in MD as in RO or FO because of the limited effect of hydraulic pressure drop through the foulant on vapor pressure, as shown in Eq. 2 (see Sec. 2.4). However, the cake thickness in the MD trial (estimated from gel mass, assuming density equal to that of water) was comparable to the thermal boundary layer thickness (estimated using Eq. 9), and so cake-enhanced temperature polarization [62, 63] would be expected to contribute significantly to the flux decline in MD.

\section{Discussion}

The CTA FO membrane used in this study showed significant resistance to calcium sulfate scaling relative to the RO and MD processes, highlighting the utility of the CTA FO membrane in circumstances where scaling resistance is critical. Calcium sulfate is a potential foulant in groundwater desalination [64] and municipal wastewater reuse [65], and FO could be used to recover additional water from supersaturated concentrate streams from

\footnotetext{
${ }^{10}$ The employed method of measuring gel accumulation may not be very accurate in the FO process, as the time spent blotting the foulant may possibly allow the draw solution contained in the support layer to pull water from the gel by osmosis.
} 
groundwater or wastewater RO plants. The CTA FO membrane's resistance to calcium sulfate scaling may or may not extend to other common inorganic foulants, such as calcium carbonate, and other FO membrane materials. Future studies should compare multiple FO membrane materials using several common scalants. Future studies should additionally include pre- and post-fouling contact angle measurements and SEM imaging to enhance understanding of fouling resistance mechanisms. Although the low pressure of FO does not affect its resistance to scaling (see Sec. 2.2), FO is often operated at a lower flux than RO, which is advantageous because it reduces concentration polarization and thus lowers the saturation index of scalants at the membrane.

Of the three processes tested, MD showed the greatest resistance to organic fouling. Although alginate was the only organic foulant tested in this study, MD mitigates organic fouling in ways that can be generalized to other organic foulants. First, the high operating temperature of MD raises the diffusion coefficient of foulants, augmenting transport away from the membrane and raising the critical flux, and second, the hydraulic resistance of a foulant layer in MD has a negligible affect on flux. MD's organic fouling resistance makes it advantageous for the concentration of foods and beverages, which have high concentrations of organics. However, the observed rapid flux decline of MD membranes after the onset of scaling demonstrates that MD should be used with caution in water sources that are prone to both organic and inorganic fouling, such as municipal wastewater [65]. Furthermore, the decline in solubility of calcium sulfate (as anhydrite [53]) with temperature should be considered when operating MD at high feed temperatures above $70{ }^{\circ} \mathrm{C}$.

These results provide insight into differences in fouling and scaling behavior of RO, FO, and MD, but their applicability to real systems is somewhat limited because they are derived from small-scale, short-duration experiments with idealized feed solutions. Real feed waters often contain a mix of organic, inorganic, and microbial foulants (see, e.g., Ref. [65]), leading to more complex fouling phenomena than were observed in this study. Given that no one 
membrane process was found to perform especially well with both organic and inorganic foulants, it would be difficult to determine from these results which process would perform best with a given complex feedwater. Future larger-scale, longer-duration studies comparing the fouling behavior of different desalination systems treating real feedwaters would improve understanding of how these processes perform with important water sources such as seawater and municipal wastewater.

Fouling reversibility in response to cleaning is an important aspect of fouling resistance that was not addressed in the present study. As discussed in Secs. 2.1 and 2.2, both organic and inorganic foulants have been previously shown to be easier to remove in FO than in RO. However, we are not aware of any direct experimental comparisons of fouling removal in MD versus RO or FO. Future research in this area will help guide desalination process choice for high-fouling applications. Furthermore, isolation of factors affecting fouling reversibility in one process may reveal insights that enable more effective cleaning in other processes.

When choosing a separation process, fouling resistance should be weighed against energy consumption. Although FO and MD each showed enhanced resistance to one type of fouling relative to $\mathrm{RO}$, both processes generally require more energy than $\mathrm{RO}$ to desalinate a wide range of feedwaters $[4,5,6,7]$. In applications where the feed osmotic pressure is too high for conventional RO, ${ }^{11}$ such as desalination of produced water from hydraulic fracturing [4], the scaling resistance of FO or the organic fouling resistance of MD may influence process choice. FO and MD may also be used for feeds that are prone to such severe inorganic or organic fouling, respectively, that higher fouling resistance is worth the price of higher energy consumption.

\footnotetext{
${ }^{11}$ Although it is not conventional to desalinate highly-concentrated feeds with RO, high-pressure RO [58] and osmotically assisted RO [66] can be used.
} 


\section{Conclusions}

The fouling propensity of RO, FO, and MD were compared using a single membrane module to simulate each type of desalination under identical hydrodynamic conditions. When filtering solutions containing sodium alginate, MD membranes exhibited significantly less flux decline (14\%) than RO or FO membranes (46\% and $47 \%$, respectively) due to the increase in solute diffusion coefficients with temperature. When calcium sulfate solutions were used, all three systems operated under somewhat supersaturated conditions for 36 hours without scaling. Scaling began to occur at significantly higher concentrations in FO (46-58 $\mathrm{mM}$ at the membrane) than in $\mathrm{RO}$ or $\mathrm{MD}(35-38 \mathrm{mM}$ in $\mathrm{RO}$ and $33-38 \mathrm{mM}$ in $\mathrm{MD})$, which may be explained by the low surface energy of CTA membranes and effect of temperature on crystallization kinetics. When gypsum scaling did occur, it triggered a much more rapid flux decline in MD than in RO or FO.

Relative to RO, both FO and MD exhibited a significant advantage in fouling resistance when exposed to a particular type of foulant: MD performed very well with alginate, which is indicative of organic fouling resistance, while the CTA FO membrane tolerated a significantly supersaturated calcium sulfate solution without scaling. However, no one system performed particularly well with both organic and inorganic foulants. Although most water and wastewater streams are complex and desalination systems must be able to tolerate a range of potential foulants, the observed differences in fouling behavior should be considered when choosing desalination processes for specific applications.

\section{Acknowledgment}

We would like to acknowledge support from the King Fahd University of Petroleum and Minerals through the Center for Clean Water and Clean Energy at MIT and KFUPM (Project \#R4-CW-11). EWT would also like to acknowledge support from the Martin Fellowship for Sustainability and acknowledge that this material is based upon work supported 
by the National Science Foundation Graduate Research Fellowship Program under Grant No. 1122374. JS and EWT would like to acknowledge funding provided by the MIT Deshpande Center for Technological Innovation. AMT would like to acknowledge funding provided by MIT's Undergraduate Research Opportunities Program.

\section{References}

[1] B. D. Coday, P. Xu, E. G. Beaudry, J. Herron, K. Lampi, N. T. Hancock, T. Y. Cath, The sweet spot of forward osmosis: Treatment of produced water, drilling wastewater, and other complex and difficult liquid streams, Desalination 333 (2014) 23-35. http://dx.doi.org/10.1016/j.desal.2013.11.014.

[2] S. Lee, C. Boo, M. Elimelech, S. Hong, Comparison of fouling behavior in forward osmosis (FO) and reverse osmosis (RO), Journal of Membrane Science 365 (2010) 34-39. http://dx.doi.org/10.1016/j.memsci.2010.08.036.

[3] D. M. Warsinger, J. Swaminathan, E. Guillen-Burrieza, H. A. Arafat, J. H. Lienhard V, Scaling and fouling in membrane distillation for desalination applications: A review, Desalination 356 (2015) 294-313. http://dx.doi.org/10.1016/j.desal.2014.06.031.

[4] G. P. Thiel, E. W. Tow, L. D. Banchik, H. W. Chung, J. H. Lienhard V, Energy consumption in desalinating produced water from shale oil and gas extraction, Desalination 366 (2015) 94-112. http://dx.doi.org/10.1016/j.desal.2014.12.038.

[5] R. K. McGovern, J. H. Lienhard V, On the potential of forward osmosis to energetically outperform reverse osmosis desalination, Journal of Membrane Science 469 (2014) 245-250. https://doi.org/10.1016/j.memsci.2014.05.061.

[6] E. W. Tow, R. K. McGovern, J. H. Lienhard V, Raising forward osmosis brine concentration efficiency through flow rate optimization, Desalination 366 (2015) 71-79. http://dx.doi.org/10.1016/j.desal.2014.10.034.

[7] D. M. Warsinger, K. H. Mistry, K. G. Nayar, H. W. Chung, J. H. Lienhard V, Entropy generation of desalination powered by variable temperature waste heat, Entropy 17 (2015) 7530-7566. http://dx.doi.org/10.3390/e17117530.

[8] T. Fujioka, N. Oshima, R. Suzuki, W. E. Price, L. D. Nghiem, Probing the internal structure of reverse osmosis membranes by positron annihilation spectroscopy: Gaining more insight 
into the transport of water and small solutes, Journal of Membrane Science 486 (2015) 106-118. http://dx.doi.org/10.1016/j.memsci.2015.02.007.

[9] J. Swaminathan, H. W. Chung, D. M. Warsinger, J. H. Lienhard V, Membrane distillation model based on heat exchanger theory and configuration comparison, Applied Energy 184 (2016) 491-505. http://doi.org/10.1016/j.apenergy.2016.09.090.

[10] J. Swaminathan, H. W. Chung, D. M. Warsinger, J. H. Lienhard V, Simple method for balancing direct contact membrane distillation, Desalination 383 (2016) 53-59. https://doi.org/10.1016/j.desal.2016.01.014.

[11] J. Swaminathan, H. W. Chung, D. M. Warsinger, J. H. Lienhard V, Energy efficiency of membrane distillation up to high salinity: Evaluating critical system size and optimal membrane thickness, Applied Energy 211 (2018) $715-734$.

[12] M. T. Ali, H. E. Fath, P. R. Armstrong, A comprehensive techno-economical review of indirect solar desalination, Renewable and Sustainable Energy Reviews 15 (2011) 4187-4199. http://dx.doi.org/10.1016/j.rser.2011.05.012.

[13] A. S. Hassan, H. E. Fath, Review and assessment of the newly developed MD for desalination processes, Desalination and Water Treatment 51 (2013) 574-585. http://dx.doi.org/10.1080/19443994.2012.697273.

[14] B. Mi, M. Elimelech, Organic fouling of forward osmosis membranes: Fouling reversibility and cleaning without chemical reagents, Journal of Membrane Science 348 (2010) 337-345. http://dx.doi.org/10.1016/j.memsci.2009.11.021.

[15] Y. Kim, M. Elimelech, H. K. Shon, S. Hong, Combined organic and colloidal fouling in forward osmosis: Fouling reversibility and the role of applied pressure, Journal of Membrane Science 460 (2014) 206-212. http://dx.doi.org/10.1016/j.memsci.2014.02.038.

[16] M. Xie, J. Lee, L. D. Nghiem, M. Elimelech, Role of pressure in organic fouling in forward osmosis and reverse osmosis, Journal of Membrane Science 493 (2015) 748-754. http://dx.doi.org/10.1016/j.memsci.2015.07.033.

[17] E. W. Tow, M. M. Rencken, J. H. Lienhard V, In situ visualization of organic fouling and cleaning mechanisms in reverse osmosis and forward osmosis, Desalination 399 (2016) 138-147. http://dx.doi.org/10.1016/j.desal.2016.08.024.

[18] E. W. Tow, J. H. Lienhard V, Quantifying osmotic membrane fouling to enable comparisons across diverse processes, Journal of Membrane Science 511 (2016) 92-107. 
http://dx.doi.org/10.1016/j.memsci.2016.03.040.

[19] W. C. L. Lay, T. H. Chong, C. Y. Tang, A. G. Fane, J. Zhang, Y. Liu, Fouling propensity of forward osmosis: investigation of the slower flux decline phenomenon., Water Science \& Technology 61 (2010) 927-936. http://dx.doi.org/10.2166/wst.2010.835.

[20] B. Mi, M. Elimelech, Gypsum scaling and cleaning in forward osmosis: Measurements and mechanisms, Environmental Science \& Technology 44 (2010) 2022-2028. http://dx.doi.org/10.1021/es903623r.

[21] D. M. Warsinger, E. W. Tow, J. Swaminathan, J. H. Lienhard V, Theoretical framework for predicting inorganic fouling in membrane distillation and experimental validation with calcium sulfate, Journal of Membrane Science 528 (2017) 381-390. https://doi.org/10.1016/j.memsci.2017.01.031.

[22] D. M. Warsinger, A. Servi, S. V. Belleghem, J. Gonzalez, J. Swaminathan, J. Kharraz, H. W. Chung, H. A. Arafat, K. K. Gleason, J. H. Lienhard V, Combining air recharging and membrane superhydrophobicity for fouling prevention in membrane distillation, Journal of Membrane Science 505 (2016) 241-252. http://doi.org/10.1016/j.memsci.2016.01.018.

[23] A. S. Myerson, R. Ginde, Handbook of Industrial Crystallization, Butterworth-Heinemann, 2nd edition, pp. 33-65.

[24] E. Curcio, X. Ji, G. Di Profio, E. Fontananova, E. Drioli, et al., Membrane distillation operated at high seawater concentration factors: role of the membrane on $\mathrm{CaCO}_{3}$ scaling in presence of humic acid, Journal of Membrane Science 346 (2010) 263-269. https://doi.org/10.1016/j.memsci.2009.09.044.

[25] Y. Baek, J. Kang, P. Theato, J. Yoon, Measuring hydrophilicity of RO membranes by contact angles via sessile drop and captive bubble method: A comparative study, Desalination 303 (2012) 23-28. http://doi.org/10.1016/j.desal.2012.07.006.

[26] E. Yang, K.-J. Chae, I. S. Kim, Comparison of different semipermeable membranes for power generation and water flux in osmotic microbial fuel cells, Journal of Chemical Technology and Biotechnology 91 (2015) 2305-2312. http://dx.doi.org/10.1002/jctb.4817.

[27] C. W. Extrand, Water contact angles and hysteresis of polyamide surfaces, Journal of Colloid and Interface Science 248 (2002) 136-142. https://doi.org/10.1006/jcis.2001.8172.

[28] M. Rezaei, D. M. Warsinger, J. H. Lienhard V, W. M. Samhaber, Wetting prevention in membrane distillation through superhydrophobicity and recharging an air layer on the membrane surface, Journal of Membrane Science 530 (2017) 42-52. https://doi.org/10.1016/j.memsci.2017.02.013.

[29] K. W. Lawson, D. R. Lloyd, Membrane distillation, Journal of Membrane Science 124 (1997) 1-25. http://dx.doi.org/10.1016/S0376-7388(96)00236-0. 
[30] L. D. Tijing, Y. C. Woo, J.-S. Choi, S. Lee, S.-H. Kim, H. K. Shon, Fouling and its control in membrane distillation-a review, Journal of Membrane Science 475 (2015) 215-244. http://dx.doi.org/10.1016/j.memsci.2014.09.042.

[31] D. M. Warsinger, A. Servi, G. B. Connors, M. O. Mavukkandy, H. A. Arafat, K. K. Gleason, J. H. Lienhard V, Reversing membrane wetting in membrane distillation: comparing dryout to backwashing with pressurized air, Environmental Science: Water Research and Technology 3 (2017) 930-939.

[32] C. Wang, C. Cowen, Z. Zhang, C. Thomas, High-speed compression of single alginate microspheres, Chemical Engineering Science 60 (2005) 6649-6657. http://dx.doi.org/10.1016/j.ces.2005.05.052.

[33] E. W. Tow, J. H. Lienhard V, Unpacking compaction: Effect of hydraulic pressure on alginate fouling, Journal of Membrane Science 544 (2017) 221-233. https://doi.org/10.1016/j.memsci.2017.09.010.

[34] E. W. Tow, J. H. Lienhard V, Effect of pressure on alginate fouling in forward osmosis, in: AMTA/AWWA Membrane Technology Conference, Long Beach, CA, USA, Feb. 13-17, 2017, Ref. \#9676-DP1964.

[35] D. Freyer, W. Voigt, Crystallization and phase stability of CaSO4 and CaSO4-based salts, Chemical Monthly 134 (2003) 693-719. https://doi.org/10.1007/s00706-003-0590-3.

[36] S. He, J. E. Oddo, M. B. Tomson, The nucleation kinetics of calcium sulfate dihydrate in $\mathrm{NaCl}$ solutions up to $6 \mathrm{~m}$ and $90^{\circ} \mathrm{C}$, Journal of Colloid and Interface Science 162 (1994) 297-303. http://dx.doi.org/10.1006/jcis.1994.1042.

[37] L. D. Nghiem, T. Cath, A scaling mitigation approach during direct contact membrane distillation, Separation and Purification Technology 80 (2011) 315-322. http://dx.doi.org/10.1016/j.seppur.2011.05.013.

[38] H. C. Duong, M. Duke, S. Gray, P. Cooper, L. D. Nghiem, Membrane scaling and prevention techniques during seawater desalination by air gap membrane distillation, Desalination 397 (2016) 92-100. http://dx.doi.org/10.1016/j.desal.2016.06.025.

[39] Y. Kim, S. Lee, H. K. Shon, S. Hong, Organic fouling mechanisms in forward osmosis membrane process under elevated feed and draw solution temperatures, Desalination 355 (2015) 169-177. http://doi.org/10.1016/j.desal.2014.10.041.

[40] W. J. Leo, A. J. McLoughlin, D. M. Malone, Effects of sterilization treatments on some properties of alginate solutions and gels, Biotechnology Progress 6 (1990) 51-53. http://dx.doi.org/10.1021/bp00001a008.

[41] E. M. V. Hoek, M. Elimelech, Cake-enhanced concentration polarization: A new fouling mech- 
anism for salt-rejecting membranes, Environmental Science and Technology 37 (2003) 5581-5588. http://dx.doi.org/10.1021/es0262636.

[42] Q. She, R. Wang, A. G. Fane, C. Y. Tang, Membrane fouling in osmotically driven membrane processes: A review, Journal of Membrane Science 499 (2016) 201-233. http://dx.doi.org/10.1016/j.memsci.2015.10.040.

[43] E. K. Summers, H. A. Arafat, J. H. Lienhard V, Energy efficiency comparison of single-stage membrane distillation (MD) desalination cycles in different configurations, Desalination 290 (2012) 54-66. http://dx.doi.org/10.1016/j.desal.2012.01.004.

[44] J. Wijmans, R. Baker, The solution-diffusion model: a review, Journal of Membrane Science 107 (1995) 1-21. http://dx.doi.org/10.1016/0376-7388(95)00102-I.

[45] E. Nagy, A general, resistance-in-series, salt- and water flux models for forward osmosis and pressure-retarded osmosis for energy generation, Journal of Membrane Science 460 (2014) 71- 81. http://dx.doi.org/10.1016/j.memsci.2014.02.021.

[46] S. Goh, Q. Zhang, J. Zhang, D. McDougald, W. B. Krantz, Y. Liu, A. G. Fane, Impact of a biofouling layer on the vapor pressure driving force and performance of a membrane distillation process, Journal of Membrane Science 438 (2013) 140-152. http://dx.doi.org/10.1016/j.memsci.2013.03.023.

[47] A. Bogler, S. Lin, E. Bar-Zeev, Biofouling of membrane distillation, forward osmosis and pressure retarded osmosis: Principles, impacts and future directions, Journal of Membrane Science 542 (2017) 378-398. http://dx.doi.org/10.1016/j.memsci.2017.08.001.

[48] J. W. Chew, W. B. Krantz, A. G. Fane, Effect of a macromolecular- or biofouling layer on membrane distillation, Journal of Membrane Science 456 (2014) 66-76. http://dx.doi.org/10.1016/j.memsci.2014.01.025.

[49] J. Lee, R. Karnik, Desalination of water by vapor-phase transport through hydrophobic nanopores, Journal of Applied Physics 108 (2010) 044315. http://dx.doi.org/10.1063/1.3419751.

[50] D. M. Warsinger, J. Swaminathan, H. W. Chung, S. Jeong, J. H. Lienhard V, The effect of filtration and particulate fouling in membrane distilliation, in: Proceedings of The International Desalination Association World Congress on Desalination and Water Reuse, San Diego, CA, USA, paper \#IDAWC15Warsinger-51667, http://hdl.handle.net/1721.1/100445.

[51] I. Braccini, S. Perez, Molecular basis of $\mathrm{Ca}^{2+}$-induced gelation in alginates and pectins: The egg-box model revisited, Biomacromolecules 2 (2001) 1089-1096. http://dx.doi.org/10.1021/bm010008g.

[52] G. P. Thiel, J. H. Lienhard V, Treating produced water from hydraulic fracturing: Composi- 
tion effects on scale formation and desalination system selection, Desalination 346 (2014) 54-69. http://dx.doi.org/10.1016/j.desal.2014.05.001.

[53] D. L. Parkhurst, C. A. J. Appelo, Description of input and examples for PHREEQC version 3-A computer program for speciation, batch-reaction, one-dimensional transport, and inverse geochemical calculations: U.S. Geological Survey Techniques and Methods, USGS, 2013. available only at https://pubs.usgs.gov/tm/06/a43/.

[54] A. L. Zydney, Stagnant film model for concentration polarization in membrane systems, Journal of Membrane Science 130 (1997) 275-281. https://doi.org/10.1016/S0376-7388(97)00006-9.

[55] W. Rohlfs, G. P. Thiel, J. H. Lienhard V, Modeling reverse osmosis element design using superposition and an analogy to convective heat transfer, Journal of Membrane Science 512 (2016) 38-49. https://doi.org/10.1016/j.memsci.2016.03.049.

[56] Y.-H. Li, S. Gregory, Diffusion of ions in sea water and in deep-sea sediments, Geochimica et Cosmochimica Acta 38 (1974) 703-714. http://dx.doi.org/10.1016/0016-7037(74)90145-8.

[57] A. F. Mills, Basic Heat and Mass Transfer, Prentice Hall, 2nd edition, 1999.

[58] R. K. McGovern, D. McConnon, J. H. Lienhard V, The effect of very high hydraulic pressure on the permeability and salt rejection of reverse osmosis membranes, in: IDA World Congress on Desalination and Water Reuse, San Diego, CA, http://web.mit.edu/lienhard/www/papers/conf/MCGOVERN_IDA_San_Diego_2015.pdf.

[59] G. Belfort, R. H. Davis, A. L. Zydney, The behavior of suspensions and macromolecular solutions in crossflow microfiltration, Journal of Membrane Science 96 (1994) 1-58. http://dx.doi.org/10.1016/03767388(94)00119-7.

[60] B. A. Qureshi, S. M. Zubair, A. K. Sheikh, A. Bhujle, S. Dubowsky, Design and performance evaluation of reverse osmosis desalination systems: An emphasis on fouling modeling, Applied Thermal Engineering 60 (2013) 208-217. http://dx.doi.org/10.1016/j.applthermaleng.2013.06.058.

[61] R. W. Field, D. Wu, J. A. Howell, B. B. Gupta, Critical flux concept for microfiltration fouling, Journal of Membrane Science 100 (1995) 259-272. https://doi.org/10.1016/0376-7388(94)00265-Z.

[62] S. Srisurichan, R. Jiraratananon, A. Fane, Mass transfer mechanisms and transport resistances in direct contact membrane distillation process, Journal of Membrane Science 277 (2006) 186-194. http://doi.org/10.1016/j.memsci.2005.10.028.

[63] M. Gryta, Fouling in direct contact membrane distillation process, Journal of Membrane Science 325 (2008) 383-394. http://doi.org/10.1016/j.memsci.2008.08.001. 
[64] D. M. Warsinger, E. W. Tow, L. A. Maswadeh, G. Connors, J. Swaminathan, J. H. Lienhard V, Inorganic fouling mitigation by salinity cycling in batch reverse osmosis, Water Research, accepted for publication (2018).

[65] M. T. Khan, M. Busch, V. G. Molina, A.-H. Emwas, C. Aubry, J.-P. Croue, How different is the composition of the fouling layer of wastewater reuse and seawater desalination RO membranes?, Water Research 59 (2014) 271-282. https://doi.org/10.1016/j.watres.2014.04.020.

[66] T. V. Bartholomew, L. Mey, J. T. Arena, N. S. Siefert, M. S. Mauter, Osmotically assisted reverse osmosis for high salinity brine treatment, Desalination 421 (2017) 3-11.

\section{Appendix A. Experimental conditions}

Tables A.3 and A.4 contain the experimental conditions of all scaling and organic fouling trials, respectively. Operating conditions (e.g., temperature) refer to the bulk feed at the module outlet. Operating pressure (reported as gauge pressure) varied between RO experiments because of differences in membrane permeability between two sheets ordered on different dates. Pressure in FO and MD experiments is reported as 0 bar because the needle did not move from the zero position on the pressure gauge in these trials; however, pressures below approximately 0.25 bar were not readable using the $0-100$ bar analog pressure gauge. Initial flux was reported after cross-flow velocity was adjusted to $5 \mathrm{~cm} / \mathrm{s}$ and before fouling began. Although not included in Table A.4, the feed solution in all organic fouling trials contained $200 \mathrm{mg} / \mathrm{L}$ sodium alginate, $1 \mathrm{mM} \mathrm{CaCL} 2$, and $50 \mathrm{mM} \mathrm{NaCl}$. 
Table A.3: Inorganic fouling experimental conditions

\begin{tabular}{cccccc}
\hline System & {$\left[\mathrm{CaSO}_{4}\right]_{\text {bulk }}(\mathrm{mM})$} & Temp. $\left({ }^{\circ} \mathrm{C}\right)$ & Pressure (bar) & Initial flux $(\mathrm{LMH})$ & Fouled? \\
\hline RO & 15.2 & 20 & 13.75 & 19.4 & No \\
RO & 19.3 & 20 & 13.75 & 19.7 & No \\
RO & 21.6 & 20 & 13.75 & 19.7 & No \\
RO & 23.7 & 20 & 23 & 19.7 & Yes \\
RO & 29.3 & 20 & 27.5 & 19.3 & Yes \\
FO & 23.7 & 20 & 0 & 20.2 & No \\
FO & 29.3 & 20 & 0 & 19.0 & No \\
FO & 36.3 & 20 & 0 & 19.4 & Yes \\
FO & 43.5 & 20 & 0 & 18.7 & Yes \\
MD & 23.7 & 60 & 0 & 19.0 & No \\
MD & 26.5 & 60 & 0 & 16.3 & No \\
MD & 29.3 & 60 & 0 & 18.9 & Yes \\
MD & 36.3 & 60 & 0 & 20.2 & Yes \\
\hline
\end{tabular}

Table A.4: Organic fouling experimental conditions.

\begin{tabular}{cccc}
\hline System & Temp. $\left({ }^{\circ} \mathrm{C}\right)$ & Pressure (bar) & Initial flux (LMH) \\
\hline RO & 25 & 16.25 & 17.1 \\
FO & 25 & 0 & 18.7 \\
MD & 60 & 0 & 16.8 \\
\hline
\end{tabular}

